\title{
Keeping Time in the Brain: Autism Spectrum Disorder and Audiovisual Temporal Processing
}

\author{
Ryan A. Stevenson, Magali Segers, Susanne Ferber, Morgan D. Barense, Stephen Camarata, and \\ Mark T. Wallace
}

\begin{abstract}
A growing area of interest and relevance in the study of autism spectrum disorder (ASD) focuses on the relationship between multisensory temporal function and the behavioral, perceptual, and cognitive impairments observed in ASD. Atypical sensory processing is becoming increasingly recognized as a core component of autism, with evidence of atypical processing across a number of sensory modalities. These deviations from typical processing underscore the value of interpreting ASD within a multisensory framework. Furthermore, converging evidence illustrates that these differences in audiovisual processing may be specifically related to temporal processing. This review seeks to bridge the connection between temporal processing and audiovisual perception, and to elaborate on emerging data showing differences in audiovisual temporal function in autism. We also discuss the consequence of such changes, the specific impact on the processing of different classes of audiovisual stimuli (e.g. speech vs. nonspeech, etc.), and the presumptive brain processes and networks underlying audiovisual temporal integration. Finally, possible downstream behavioral implications, and possible remediation strategies are outlined. Autism Res 2015, 00: 000-000. (C) 2015 International Society for Autism Research, Wiley Periodicals, Inc.
\end{abstract}

Keywords: low-level perception; cognitive neuroscience; developmental psychology; social cognition

Autism spectrum disorder (ASD) is a neurodevelopmental disorder of high prevalence, estimated at rates as high as 1 in 68 in all children and 1 in 42 for boys, and is associated with enormous economic, societal, and individual costs [ADDM, 2014; Baio, 2012]. ASD is characterized by atypical social communication and restricted and repetitive interests [APA, 2013]. In addition to being part of the original description of Autism [Kanner, 1943], sensory and perceptual disruptions are now a core diagnostic criteria in ASD (DSM-5). These sensory changes are typically seen in more than a single sensory modality, extending to multiple sensory systems including vision, hearing, touch, proprioception, taste, and smell [Baranek, David, Poe, Stone, \& Watson, 2006; Dawson \& Watling, 2000; Kasari \& Sigman, 1997; Kern et al., 2007; Kientz \& Dunn, 1997; O'Neill \& Jones, 1997; Rogers, Hepburn, \& Wehner, 2003; TalayOngan \& Wood, 2000; Watling, Deitz, \& White, 2001; Wing \& Potter, 2002]. The ubiquity of these sensoryprocessing differences across multiple modalities within individuals with ASD suggests that they play an impor- tant role in the lived experiences of individuals with ASD and should be considered from a multisensory perspective [for review see Baum, Stevenson, \& Wallace, In Press]. In fact, emerging evidence strongly supports the presence of specific multisensory processing deficits in ASD. These deficits extend beyond those predicted on the basis of changes within the individual sensory modalities in response to audiovisual processing [Brandwein et al., 2012; Ross et al., 2011; Stevenson et al., 2014a], audiotactile processing [Russo et al., 2010], and visuohaptic processing [Cascio, Foss-Feig, Burnette, Heacock, \& Cosby, 2012].

The impact of multisensory integration on behavioral, perceptual, and cognitive processes is quite significant [for review, see Stevenson, Ghose, et al., 2014]. The vast majority of inputs that an individual receives from the external world are informed and guided by sensory information from multiple modalities. Despite the presence of distinct receptor organs and input streams for the different senses, our perceptual view of the world is unified. Perceptual unification can be seen

From the Department of Psychology, University of Toronto, Toronto, Ontario, Canada (R.A.S., S.F., M.D.B.); Department of Psychology, York University, Toronto, Ontario, Canada (M.S.); Rotman Research Institute, Toronto, Ontario, Canada (S.F., M.D.B.); Department of Hearing and Speech Sciences, Vanderbilt University Medical Center, Nashville, Tennessee (S.C., M.T.W.); Vanderbilt Kennedy Center, Vanderbilt University Medical Center, Nashville, Tennessee (S.C., M.T.W.); Vanderbilt Brain Institute, Vanderbilt University Medical Center, Nashville, Tennessee (M.T.W.); Department of Psychology, Vanderbilt University, Nashville, Tennessee (M.T.W.); Department of Psychiatry, Vanderbilt University Medical Center, Nashville, Tennessee (M.T.W.)

Received April 14, 2015; accepted for publication August 29, 2015

Address for correspondence and reprints: Ryan Stevenson, Department of Psychology, University of Toronto, Toronto, ON, Canada. E-mail: ryan.andrew.stevenson@gmail.com

Published online 00 Month 2015 in Wiley Online Library (wileyonlinelibrary.com)

DOI: $10.1002 /$ aur.1566

(C) 2015 International Society for Autism Research, Wiley Periodicals, Inc. 


\section{A. Typical Temporal Binding}

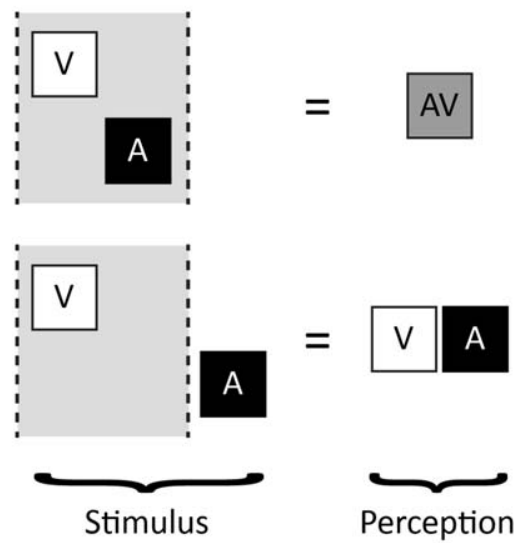

B. Atypical Temporal Binding

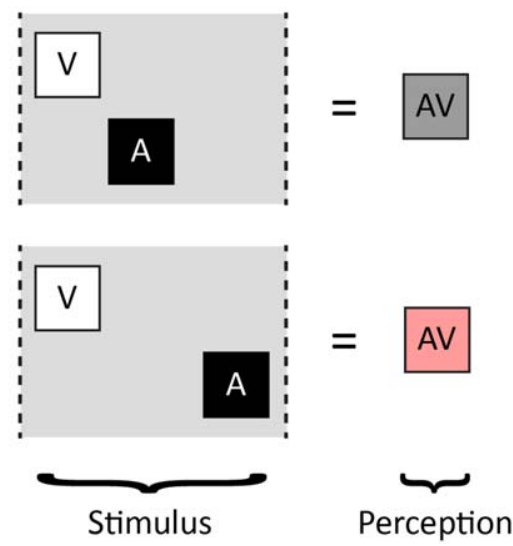

Figure 1. The temporal synchrony of two incoming sensory inputs is a salient cue as to whether the two inputs should be perceptually bound. In a typically developed perceptual system, perceptual binding occurs within a limited range of temporal offsets between the two inputs. Outside that widow of time, the inputs are likely to be processed as independent units of information (Panel A). The width of this window is reflective of environmental statistics. Individuals with ASD often exhibit atypically wide TBWs, resulting in the perceptual binding of sensory inputs that likely did not originate from the same external event (pink) (Panel B). A, auditory; V, visual; AV, audiovisual.

through illusory examples such as the McGurk Effect. In this illusion, a listener is presented with a video of a speaker who articulates the syllable "ga" and an auditory track of the speaker uttering a temporally aligned "ba" [MacDonald \& McGurk, 1978; McGurk \& MacDonald, 1976]. Often, the listener will report having perceived "da" or "tha," syllables contained in neither the auditory nor the visual sensory streams. Such instances represent a perceptual synthesis-a merging of information across sensory modalities. Integrating information across the different senses results not only in interesting illusions, but also provides a host of behavioral benefits, from simple gains in response times [Diederich \& Colonius, 2004; Gondan, Niederhaus, Rosler, \& Roder, 2005; Hershenson, 1962; Hughes, Reuter-Lorenz, Nozawa, \& Fendrich, 1994; Miller, 1982; Molholm et al., 2002; Murray, Foxe, Higgins, Javitt, \& Schroeder, 2001; Schroger \& Widmann, 1998], rates of detection [Bolognini, Frassinetti, Serino, \& Ladavas, 2005; Lovelace, Stein, \& Wallace, 2003; Stein, Meredith, Huneycutt, \& McDade, 1989], and spatial localization [Stein, Huneycutt, \& Meredith, 1988; Stevenson, Fister, et al., 2012], to higher order functional benefits such as improved speech perception in noise [Sumby \& Pollack, 1954].

To benefit from multiple streams of information, an individual must properly assess sensory signals. When signals originate from the same external event they should be bound into a unified percept, but when signals originate from distinct external events they should be processed distinctly. This decision process is commonly referred to as the "binding problem," and has received much attention across a variety of disciplines [Treisman, 1996]. One of the most important pieces of information that an individual uses to make this perceptual "decision" is the temporal relationship between incoming sensory signals. Sensory signals that originate from a single external event will have highly related temporal structures including, but not limited to, the timing of signal onset and offset. In contrast, sensory signals that originate from two distinct external events are much less likely to have related temporal structures. Reflecting these environmental statistics, two sensory signals that are in close temporal proximity are more likely to be perceptually bound across a range of different stimulus types, including speech [Conrey \& Pisoni, 2006; Dixon \& Spitz, 1980; Hillock, Powers, \& Wallace, 2011; Stevenson, Altieri, Kim, Pisoni, \& James, 2010; Stevenson, VanDerKlok, Pisoni, \& James, 2011; Stevenson \& Wallace, 2013; van Atteveldt, Formisano, Blomert, \& Goebel, 2007; van Wassenhove, Grant, \& Poeppel, 2007], tools [Stevenson \& James, 2009; Stevenson \& Wallace, 2013], and very simple stimuli, e.g. flashes and beeps [Conrey \& Pisoni, 2006; Hillock et al., 2011; Keetels \& Vroomen, 2005; Powers, Hillock, \& Wallace, 2009; Stevenson \& Wallace, 2013; Stevenson, Wilson, Powers, \& Wallace, 2013; Stevenson, Zemtsov, \& Wallace, 2012; Wallace et al., 2004; Zampini, Guest, Shore, \& Spence, 2005]. Signals close in temporal proximity are also more likely to induce the aforementioned behavioral benefits [Macaluso, George, Dolan, Spence, \& Driver, 2004; Meredith, Nemitz, \& Stein, 1987; Meredith, Wallace, \& Stein, 1992; Miller \& D'Esposito, 2005; Royal, Carriere, \& Wallace, 2009; Schall, Quigley, Onat, \& Konig, 2009; Senkowski, Talsma, Grigutsch, Herrmann, \& Woldorff, 2007; Stevenson et al., 2010; Stevenson et al., 2011] when compared with the same two sensory 
signals that are temporally disparate (Fig. 1A). However, the two inputs do not have to be perfectly temporally aligned to be bound. Rather, these inputs must occur within an epoch or "window" of time that is now commonly referred to as the temporal binding window (TBW) [Colonius \& Diederich, 2004; Hairston, Burdette, Flowers, Wood, \& Wallace, 2005].

In typically developing (TD) individuals, multisensory integration allows one to efficiently process the continual stream of sensory information. In individuals with ASD, however, this process is less efficient. For example, atypical multisensory integration can be seen in responses to the McGurk effect described above. Several studies have found that children with ASD show reduced levels of integration and as a result are less susceptible to the illusion [e.g. Bebko, Schroeder, \& Weiss, 2014; de Gelder, Vroomen, \& Van der Heide, 1991; Irwin, Tornatore, Brancazio, \& Whalen, 2011; Mongillo et al., 2008; Stevenson, Siemann, et al., 2014; Stevenson et al., 2014b; Williams, Massaro, Peel, Bosseler, \& Suddendorf, 2004]; but see [Iarocci, Rombough, Yager, Weeks, \& Chua, 2010; Woynaroski et al., 2013]. Typically, this reduction in perceptual binding is the result of an over-reliance on the auditory signal and a reduced reliance on visual speech information [Iarocci et al., 2010; Irwin et al., 2011; Mongillo et al., 2008; Stevenson, Siemann, et al., 2014; Stevenson et al., 2014b]. This reliance on a single sensory modality suggests that the visual and auditory stimulus components are being processed independently, rather than being integrated.

As previously described, one of the most salient features as to whether two stimulus inputs will be perceptually bound is their temporal coincidence. However, in order to take advantage of the predictive nature of such synchrony, the perceiver must be able to accurately process this temporal information (Fig. 1B). In fact, recent evidence has shown that typically developed individuals who show less acute multisensory temporal processing are less likely to perceive the McGurk Effect [Stevenson, Zemtsov, et al., 2012]. This study suggests that precise temporal processing results in temporal synchrony being a strong and reliable cue to bind, leading to an increase in the ability to properly perceptually bind synchronous auditory and visual information. The fact that temporal processing is linked to multisensory integration is particularly relevant in autism, as ASD is often associated with decreased temporal precision and reliability [Brock, Brown, Boucher, \& Rippon, 2002; Cardy, Flagg, Roberts, Brian, \& Roberts, 2005; McPartland, Dawson, Webb, Panagiotides, \& Carver, 2004; Szelag, Kowalska, Galkowski, \& Pöppel, 2004]. Most germane is the temporal binding hypothesis of ASD, introduced by Brock and colleagues [2002], which posits that symptoms of ASD result from reduced neural integration with local neural networks due to a decrease in synchronization of high-frequency gamma activity. The findings that individuals with ASD tend to show decreases in multisensory integration coupled with atypical temporal processing lead to the hypothesis that atypical temporal processing in ASD plays a causal role in the observed multisensory integration weaknesses [Stevenson, Siemann, et al., 2014]. Here, we will review the relevant empirical investigations (Table 1) in order to consolidate and inform the field's current understanding of multisensory temporal processing in highfunction individuals with ASD. These studies will be broken into three sections: eye-gaze studies, behavioral studies that indirectly or implicitly inquire about multisensory integration using audiovisual illusions, and behavioral studies that directly and explicitly probe for temporal aspects of audiovisual integration, including studies using simultaneity judgments and temporal order judgments.

\section{Eye-Gaze Studies}

The first study directly investigating the perception of temporal synchrony across audition and vision in ASD was performed by Bebko, Weiss, Demark, and Gomez [2006]. Using a preferential-looking paradigm (as measured objectively via Noldus Observer), 4- to 6-year olds (Vineland Adaptive Language Level range $=0.8-3.1$ years old) looked at two monitors presenting the same visual stimuli and a single auditory presentation. One screen had a visual display that was temporally synchronized with the auditory track, and the second screen's visual presentation was 3 sec advanced (visual preceding audio-VA). Three distinct categories of stimuli were presented: complex-speech consisting of a story being read, simple-speech consisting of a series of numbers being read, and nonspeech consisting of the children's game Mousetrap. Both groups showed preferential looking toward synchronous stimuli when presented with the nonspeech stimuli (i.e., Mousetrap). However, a different pattern emerged with speech stimuli, whereby TD children continued to preferentially look toward the screen with the synchronous visual presentation, but children with ASD viewed the screens equally (Fig. 2A). This pattern was consistent across both the simple and complex speech conditions. These results highlight two key findings. First, it demonstrated that individuals with ASD do not spontaneously prefer audiovisual synchrony, thus providing the first evidence that individuals with ASD may in fact show atypical temporal perception across sensory modalities. Second, this study also revealed that these atypicalities were dependent upon stimulus type. It should be noted that this paradigm cannot definitively inform us as to whether this difference was due to the inclusion of 
Table 1. Studies of Multisensory Temporal Perception in Autism Spectrum Disorders

\begin{tabular}{|c|c|c|c|c|c|c|}
\hline Article & Age (years) & Measure & Stimuli & Task & SOAs (ms) & Group difference \\
\hline $\begin{array}{l}\text { Bebko et al., Journal } \\
\text { of Child Psychol- } \\
\text { ogy and Psychia- } \\
\text { try, } 2006\end{array}$ & $4-6$ & Eye tracking & $\begin{array}{l}\text { Mousetrap } \\
\text { Counting speech } \\
\text { Sentences }\end{array}$ & Undirected watching & $3,000 \mathrm{VA}$ & $\begin{array}{l}\text { No } \\
\text { Yes } \\
\text { Yes }\end{array}$ \\
\hline $\begin{array}{l}\text { Grossman et al., } \\
\text { Autism Research, } \\
2015\end{array}$ & $8-19$ & Eye tracking & Sentences & $\begin{array}{l}\text { Undirected watching } \\
\text { Directed watching }\end{array}$ & $330 \mathrm{VA}$ & $\begin{array}{l}\text { Yes } \\
\text { Yes }\end{array}$ \\
\hline $\begin{array}{l}\text { Patten et al., Autism } \\
\text { Research and } \\
\text { Treatment, } 2014\end{array}$ & $3-6$ & Eye tracking & $\begin{array}{l}\text { Auditory speech and } \\
\text { visual doll } \\
\text { movements }\end{array}$ & Undirected watching & $700 \mathrm{AV}$ & $\mathrm{N} / \mathrm{A}$ \\
\hline $\begin{array}{l}\text { Foss-Feig et al., } \\
\text { Experimental Brain } \\
\text { Research, } 2010\end{array}$ & $8-17$ & Illusion & Flashes and beeps & $\begin{array}{l}\text { Sound-induced Flash } \\
\text { Illusion }\end{array}$ & $0-500 \mathrm{AV}, 0-500 \mathrm{VA}$ & Yes \\
\hline $\begin{array}{l}\text { Collignon et al., } \\
\text { Cortex, } 2013\end{array}$ & $14-31$ & Illusion & Lines and tones & Visual search & $\mathrm{N} / \mathrm{A}$ & Yes \\
\hline $\begin{array}{l}\text { Kwakye et al., } \\
\text { Frontiers in } \\
\text { Psychology, } 2012\end{array}$ & $8-17$ & Illusion & Flashes and beeps & $\begin{array}{l}\text { Visual temporal order } \\
\text { judgment }\end{array}$ & $0-500 \mathrm{VA}$ & Yes \\
\hline $\begin{array}{l}\text { Woynaroski et al., } \\
\text { Journal of Autism } \\
\text { and Developmental } \\
\text { Disorders, } 2013\end{array}$ & $8-17$ & Illusion & $\begin{array}{l}\text { Single phoneme } \\
\text { speech }\end{array}$ & McGurk Effect & $0-300$ VA & Yes \\
\hline $\begin{array}{l}\text { Grossman et al., } \\
\text { Journal of Child } \\
\text { Psychology and } \\
\text { Psychiatry, } 2009\end{array}$ & $14.5^{\mathrm{a}}$ & Direct perception & Sentences & $\begin{array}{c}\text { Simultaneity } \\
\text { judgment }\end{array}$ & $0-500 \mathrm{VA}$ & No \\
\hline $\begin{array}{l}\text { de Boerscellekens } \\
\text { et al., Frontiers in } \\
\text { Psychology, } 2013\end{array}$ & $16-22$ & Direct perception & $\begin{array}{l}\text { Flashes and beeps } \\
\text { Hand claps } \\
\text { Single phoneme } \\
\text { speech }\end{array}$ & $\begin{array}{l}\text { Audiovisual temporal } \\
\text { order judgment }\end{array}$ & $0-320 \mathrm{AV}, 0-320 \mathrm{VA}$ & $\begin{array}{l}\text { Yes } \\
\text { Yes } \\
\text { Yes }\end{array}$ \\
\hline $\begin{array}{l}\text { Stevenson et al., } \\
\text { Journal of } \\
\text { Neuroscience, } \\
2014\end{array}$ & $6-18$ & Direct perception & $\begin{array}{l}\text { Flashes and beeps } \\
\text { Handheld tools } \\
\text { Single phoneme } \\
\text { speech }\end{array}$ & $\begin{array}{c}\text { Simultaneity } \\
\text { judgment }\end{array}$ & $\begin{array}{l}0-300 \mathrm{AV}, 0-300 \mathrm{VA} \\
0-300 \mathrm{AV}, 0-300 \mathrm{VA} \\
0-400 \mathrm{AV}, 0-400 \mathrm{VA}\end{array}$ & $\begin{array}{l}\text { No } \\
\text { No } \\
\text { Yes }\end{array}$ \\
\hline $\begin{array}{l}\text { Donohue et al., } \\
\text { Experimental Brain } \\
\text { Research, } 2012\end{array}$ & $21.5^{\mathrm{a}}$ & Direct perception & Flashes and beeps & $\begin{array}{c}\text { Simultaneity } \\
\text { judgment }\end{array}$ & $0-300 \mathrm{AV}, 0-300 \mathrm{VA}$ & $\mathrm{N} / \mathrm{A}$ \\
\hline
\end{tabular}

SJ, simultaneity judgment; TOJ, temporal order judgment; AV, auditory preceding visual; VA, visual preceding auditory.

${ }^{a}$ Indicated mean age, as age range was unreported.

language or due to the inclusion of social factors (e.g. including a face) as they were not separated experimentally, but it did identify that there was a clear difference related to one of, if not all of, these factors.

A more recent eye-gaze study conducted by Grossman, Steinhart, Mitchell, and Mcllvane [2015] with infrared-based eye tracking used a single auditory track of a speaker saying short sentences and two screens showing the speaker's face articulating the sentences. One visual presentation, at any given time, was synchronized with the auditory presentation. The other presentation had a $330 \mathrm{~ms}$ visual lag (audio preceding visual-AV). In addition, this study used two other manipulations: an implicit condition in which participants were simply instructed to watch the videos, and an explicit condition in which participants were instructed to watch the synchronized video. While both children with and without ASD (8-19 years old, mean verbal IQ not reported, Peabody Picture Vocabulary Test score of receptive vocabulary $=107$ ) looked toward the synchronous video more than the asynchronous video in all conditions, children without ASD looked at the synchronized screen significantly more than their counterparts with ASD in both conditions. Also, TD children but not children with ASD showed increased viewing to the synchronized video in the explicit condition relative to the implicit condition. Thus, this study confirmed the finding that children with ASD were less sensitive to temporal synchrony of audiovisual speech, and extended the previous results to show that children with ASD had difficulties detecting synchrony even when explicitly tasked with attending to the temporal properties of the presentations. Furthermore, this convergent evidence was found 


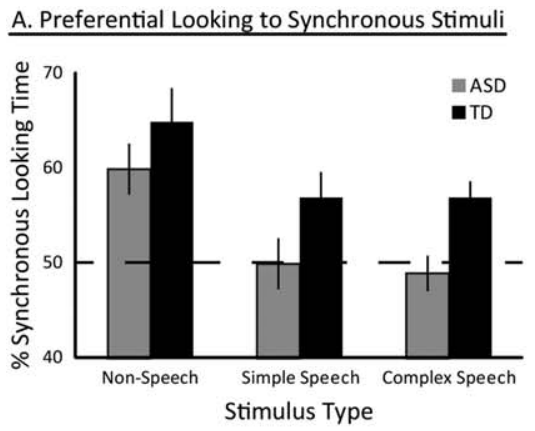

D. Multisensory gains in accuracy and response times across SOAs
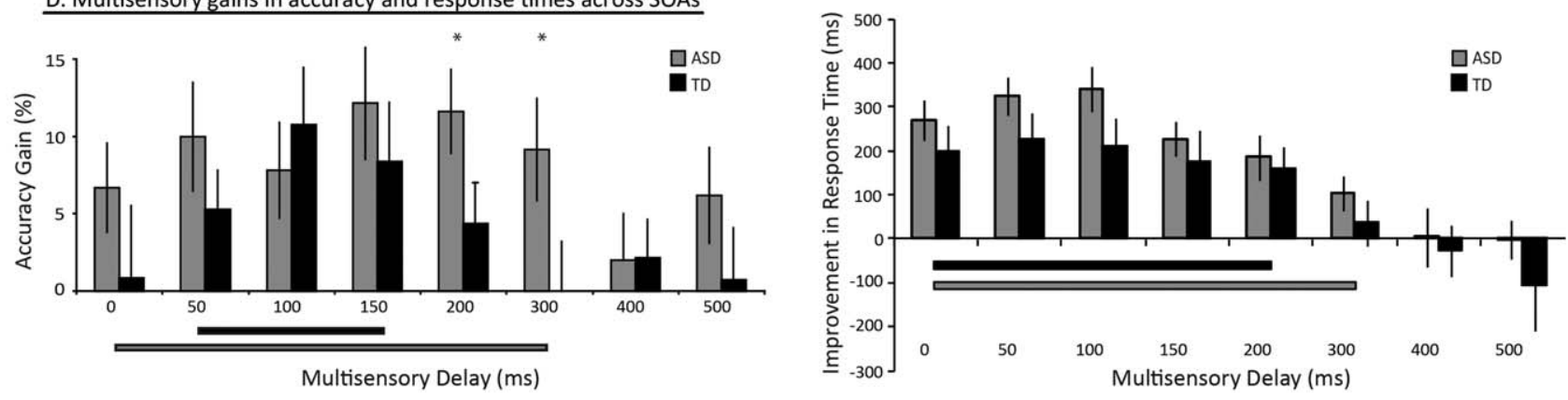

Figure 2. Indirect measures of multisensory temporal processing. Panel A depicts data showing that young individuals with ASD were impaired in detecting synchrony of speech but not nonspeech audiovisual inputs as measured with eye-tracking [adapted from Bebko et al., 2006]. Error bars represent standard deviation. Panels B and C present data showing that individuals with ASD perceive multisensory illusions implying perceptual binding even when the auditory and visual stimulus components are presented with large temporal disparities, suggesting a wider TBW for these individuals [adapted from Foss-Feig et al., 2010; Woynaroski et al., 2013]. Error bars represent standard error. Panel $D$ shows that multisensory integration in individuals with ASD impacts both accuracy and response times over a wider range of temporal offsets [adapted from Kwakye et al., 2011]. Error bars represent standard error.

despite a number of methodological differences relative to the previously discussed study [Bebko et al., 2006], including using different stimuli, having an auditory lead as opposed to a visual lead, different manners of coding of gaze patterns (Noldus Observer vs. infraredbased eye tracking), and differing task demands.

A third eye-gaze study measured the relationship between synchrony detection and language abilities in children with ASD (3-6 years old, verbal IQ not reported, mean Preschool Language Test-4 receptive language score $=38$, receptive language ratio (PLS-4/chronological age) $=0.69$ ) [Patten, Watson, \& Baranek, 2014]. While this study again used a preferential-looking paradigm, the stimuli were substantially different from those used in the previously described studies. Visual stimuli consisted of a doll on a speaker's lap, but with the speaker's face excluded from the video. In the synchronous condition, the doll was bounced when the speaker said the doll's name. In the asynchronous condition, the doll was bounced 700 ms before the doll's name was said (visual preceding audio-VA). Thus, while the stimuli included speech, the temporal alignment was not between auditory speech and the speaker's mouth, but between auditory speech and the movement of a children's toy. Children with ASD preferentially looked at synchronized videos (55\% of viewing to synchronous videos, $45 \%$ viewing of asynchronous videos). As there was no control group, differences between children with and without ASD could not be measured, limiting the interpretation of these findings. While group differences could not be assessed, the inclusion of language measures allowed for the assessment of the relationship between synchronydetection and receptive language proficiency (the ability to understand or comprehend language). Indeed, a significant correlation between time spent looking at the synchronous video and receptive language proficiency was found-the more looking toward the synchronous presentation, the higher the receptive language scores in children with ASD. This finding supports the hypothesis that lower-level multisensory temporal perception may have a cascading impact on higher-ordered cognitive functioning, such as receptive language abilities [Stevenson, Segers, et al., 2014].

This finding opens a number of avenues for future research. First, the relationship between synchrony detection and receptive language in children with ASD is interesting, but it remains to be seen if this relationship is observed in all children, both with and without ASD, or if this relationship is a product of atypical sensory processing in children with ASD. A single paper, Grossman 
Schneps, and Tager-Flusberg [2009], conducted such an analysis, and found no such relationship. However, this single paper also showed no relationship between synchrony detection and receptive language in TD children, nor a group difference in synchrony detection of speech between ASD and TD groups, contrary to what all other studies have shown. As such, future studies utilizing a TD control group are needed to be able to make this distinction reliably. Second, as this study paired auditory speech with the movement of a children's toy, it remains to be seen if attending to synchronized auditory speech and the associated visual mouth movements would also show the same relationship with receptive language abilities. If anything, one would hypothesize that this relationship should be stronger. However, as seen with the Bebko et al. [2006] study, individuals with ASD respond very differently to different classes of stimuli.

\section{Behavioral Studies: Audiovisual Illusions}

Differential sensory processing for particular types of stimuli in ASD is a consistent finding. In general, individuals with ASD have shown intact or even enhanced processing of simple stimuli, whereas processing of more complex stimuli is often impaired [Bertone, Mottron, Jelenic, \& Faubert, 2005; Minshew \& Hobson, 2008]. There also may be a difference specifically related to speech information, which tends to be impaired, whereas nonspeech stimuli tend to show less dramatic differences [Mongillo et al., 2008]. Speech perception is, however, inherently complex, and parsing of the possibly independent effects of complexity and speech is still ongoing. The pattern of greater impairments for more complex stimuli also applies to multisensory illusions. As previously discussed, research shows that the McGurk Effect, a speech-related multisensory illusion, is generally weaker in individuals with ASD [Bebko et al., 2014; de Gelder et al., 1991; Irwin et al., 2011; Mongillo et al., 2008; Stevenson, Siemann, et al., 2014; Stevenson et al., 2014b; Williams et al., 2004; but see Iarocci et al., 2010; Woynaroski et al., 2013]. In contrast to the McGurk effect, the sound-induced flash illusion [Shams, Kamitani, \& Shimojo, 2000] uses nonspeech stimuli to assess binding of information across sensory modalities: a single visual flash presented with multiple auditory beeps induces the illusory visual perception of multiple flashes. Multiple studies show this illusion is intact in adults with ASD [Keane, Rosenthal, Chun, \& Shams, 2010; van der Smagt, van Engeland, \& Kemner, 2007], although one study indicates that this may not be the case in children with ASD [Stevenson et al., 2014a].

The sound-induced flash illusion has also been adapted to explicitly examine multisensory temporal processing in children with and without ASD (8-17 years old, mean verbal $\mathrm{IQ}=105$, typical reading abilities) [Foss-Feig et al., 2010]. In this study, a single visual flash was paired with two auditory beeps while varying the timing of the beeps relative to the flash. While one beep was always presented simultaneously with the visual flash, the stimulus onset asynchrony (SOA) of the second beep was systematically varied from $500 \mathrm{~ms}$ preceding the visual flash to $500 \mathrm{~ms}$ following the visual flash. Participants were tasked with counting the number of visual flashes they saw, and explicitly asked to ignore the auditory beeps. Given that the perception of illusory flashes can serve as a proxy for multisensory binding, Foss-Feig and colleagues [2010] were able to determine the temporal offsets at which individuals perceptually bound auditory and visual inputs-in essence measuring the multisensory TBW. Individuals with ASD showed a wider TBW than TD individuals, reflecting less precise multisensory temporal processing (Fig. 2B). Collectively, these results suggest that individuals with ASD may be binding together stimuli that should not be bound.

It is important to note here that even typically developing individuals have TBWs that span several hundred milliseconds. Although seemingly counterintuitive, such a window makes good ecological sense given the structure of our sensory world. That is, given differences in propagation speeds of visual and auditory stimulus energies, auditory sensory signals will reach the cochlea slightly after the visual signal reaches the retina because light travels faster than sound. Additionally, this auditory-visual lag increases as stimulus distance grows [Pöppel, Schill, \& von Steinbüchel, 1990]. There are also substantial differences in the timing of the acoustic and visual transduction processes, as well as in neural conduction times for the different modalities [Corey \& Hudspeth, 1979; King \& Palmer, 1985; Lamb \& Pugh, 1992; Lennie, 1981]. For these reasons, it is advantageous that two sensory inputs may still be bound if they are in relatively close temporal proximity even if they are not perfectly synchronous. The more temporally proximate two inputs are, the greater the chance of integration [Vroomen \& Keetels, 2010]. The TBW characterizes the relationship between two inputs from different modalities as a probabilistic concept reflecting the likelihood that the inputs will or will not result in alterations in behavior and/or perception across a range of SOAs.

A follow-up paper to this sound-induced flash illusion study reported corroborating findings using a different paradigm [Kwakye, Foss-Feig, Cascio, Stone, \& Wallace, 2011]. In this study, children with and without ASD (8-17 years old, typical reading levels, no report of verbal IQ or verbal language abilities) completed a visual temporal order judgment task. Two visual flashes were presented at different locations on a screen, and children were asked to report 
which flash came first. During a subset of trials, two auditory beeps were also presented, one synchronous with the initial visual flash, and one presented with or following the second flash by up to $500 \mathrm{~ms}$ (VA). Importantly, the addition of these auditory beeps did not contribute any relevant information for the visual task. Despite this, the inclusion of these auditory stimuli increased performance on the visual task (both in accuracy and response time), but only when the auditory cues were presented within a restricted window of time relative to the flashes [Hairston, Hodges, Burdette, \& Wallace, 2006; Hairston et al., 2005; MoreinZamir, Soto-Faraco, \& Kingstone, 2003]. Critically, the window of time in which the auditory stimuli modulated visual task performance was greater in individuals with ASD compared to their TD peers (Fig. 2D), providing converging evidence that individuals with ASD exhibit decreased multisensory temporal precision relative to their TD peers.

A third audiovisual paradigm using simple, nonspeech stimuli that contributes to this line of findings is the "pip and pop" paradigm [Van der Burg, Olivers, Bronkhorst, \& Theeuwes, 2008]. Participants are presented with an array of visual lines of various orientations and tasked with finding the vertical or horizontal target. All items alternate between two colors at random intervals. In some trials, an auditory beep, or "pip," is presented in synchrony with the visual target's color switch. This induces a pop-out effect, resulting in increased visual search accuracy and speed, indicating multisensory facilitation. Importantly, this effect only occurs when the auditory tone is presented synchronously with a visual target. As such, an individual must be able to correctly perceive the timing of the audiovisual pair in order to benefit from the audiovisual coincidence. Collignon and colleagues [2013] used this paradigm to investigate multisensory facilitation in high-functioning ASD (age range $=14-31$, mean verbal $\mathrm{IQ}=102$, no measure of receptive language). Participants were presented with item arrays of either 24, 36, or 48 visual items. In the typically developed group, when an auditory tone was presented synchronously with the visual target, significant increases in accuracy and significantly faster response times were observed. This effect was found in all set sizes. In the ASD group, however, no change in either accuracy or response time was seen in any set size, suggesting that individuals with ASD were unable to make use of the audiovisual synchrony to increase visual search efficiency.

Each of the studies described above suggest atypical multisensory temporal processing even with extremely simple stimuli, in contrast to the speech-specific differences found by Bebko et al. [2006]. This discrepancy speaks to an unresolved question as to the level at which sensory processing is first impaired in ASD. This debate over stimulus complexity notwithstanding, what has been made clear is that findings of multisensory temporal processing differences for speech stimuli in ASD are consistent and robust [but see Grossman et al., 2009]. For example, a recent study from Woynaroski et al. [2013] showed extended multisensory TBWs in ASD for McGurk-related stimuli. In this experiment, 817-years olds with and without ASD (mean verbal $\mathrm{IQ}=109$, no measure of verbal language level) were presented with standard McGurk stimuli but with visualleading SOAs up to $300 \mathrm{~ms}$. Again, individuals with ASD were more likely to report illusory perceptions at larger temporal offsets, with a 73\% increase in TBW width relative to their TD peers (Fig. 2C).

\section{Behavioral Studies: Explicit Measures of Temporal Perception}

While the above studies describe differences in multisensory temporal processing in ASD that have been demonstrated across a variety of indirect or implicit methodologies (e.g. preferential looking, illusions), a number of studies have approached the issue in a more direct, explicit manner, collecting explicit reports of temporal perceptions. The first of these was a study of adolescents with and without ASD (age range not reported, mean age $=14$ years old, mean verbal $\mathrm{IQ}=109$, Peabody Picture Vocabulary Test score of receptive vocabulary $=113$ ) by Grossman et al., [2009]. The participants watched videos of a speaker uttering short phrases, with SOAs of the visual and auditory tracks ranging from 0 to $500 \mathrm{~ms}$ with a visual lead (visual preceding audio-VA), and completed a simultaneity judgment task. There were no group differences between individuals with and without ASD. To our knowledge, this study is the only one that has failed to find group differences in temporal perception of speech stimuli between individuals with and without ASD. At the time, this was also the only study to ask participants with ASD to directly report the perception of synchrony as opposed to relying on a more indirect behavioral measure such as eye gaze, leaving open the possibility that the group differences seen in the preferential-looking tasks may have been specific to spontaneous eye gaze. Multiple recent follow-up studies have, however, proven that this was not the case.

A second study of multisensory temporal perception addressed the issue of stimulus type using three different stimulus types: simple flashes and beeps (simple nonspeech), hands clapping (complex nonspeech), and single-syllable speech utterances (complex speech) [de Boer-Schellekens, Eussen, \& Vroomen, 2013]. Participants with and without ASD (16-22 years old, verbal $\mathrm{IQ}=106$, no report of language proficiency) completed a temporal order judgment task across parametrically varied visual-leading and audio-leading SOAs of up to 


\section{A. Just Noticable Differences}

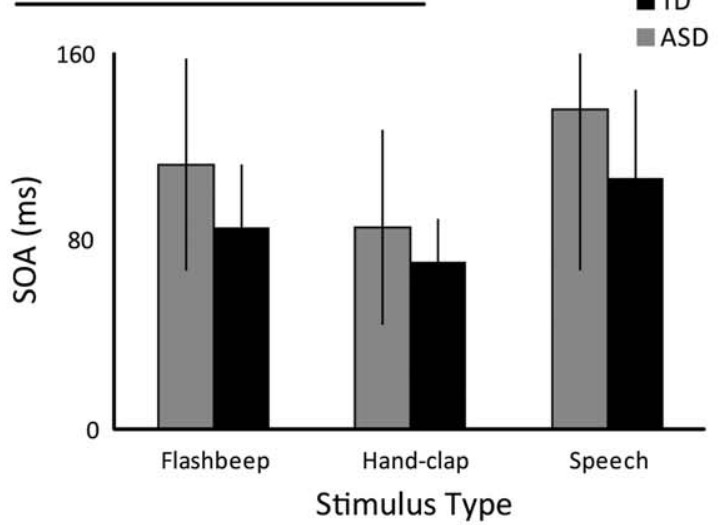

C. Temporal Binding Window Widths

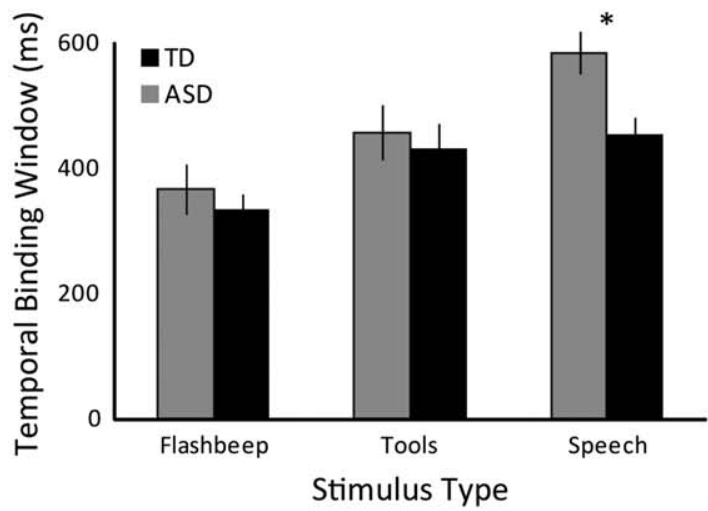

D. McGurk Effect

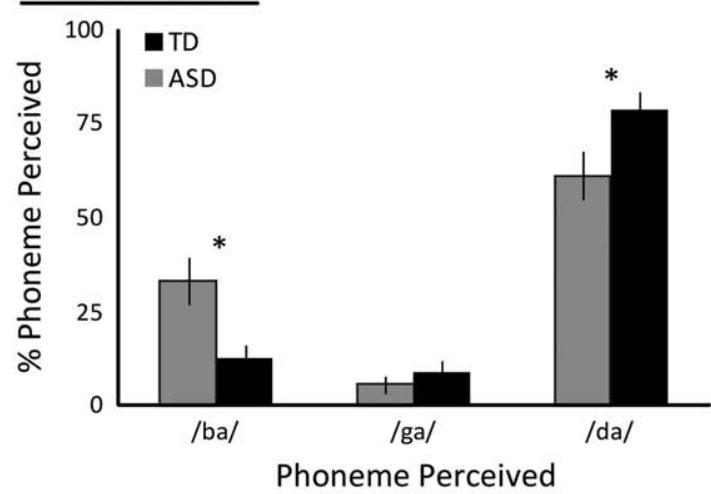

B. Point of Subjective Simultaneity

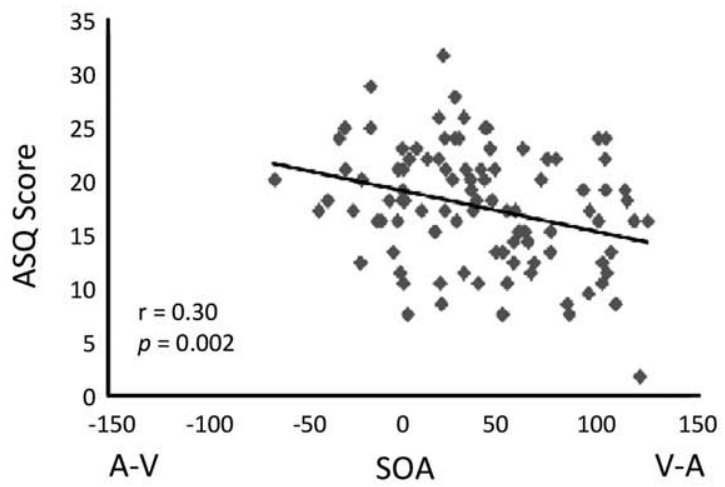

E. Temporal Processing $x$ Speech Integration in ASD

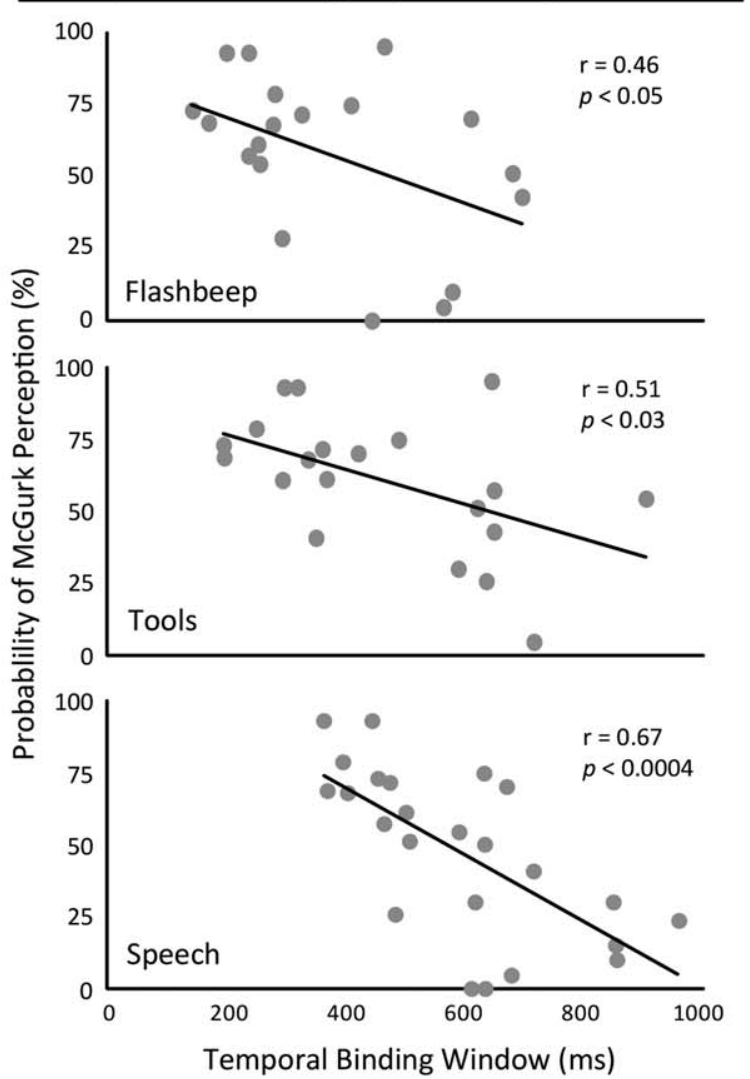

Figure 3. Direct measures of multisensory temporal processing. Panel A shows just-noticeable differences of temporal offsets between three types of stimuli across a range of complexity. Individuals with ASD show greater just noticeable differences across all stimulus types [adapted from de Boer-Schellekens et al., 2013]. Error bars represent standard error. Panel B depicts the correlation between individuals' point of subjective simultaneity and nonclinical autistic traits as measured by the Autism Spectrum Quotient; the greater the autistic traits, the more auditory-leading the individuals' point of subjective simultaneity [adapted from Donohue et al., 2012]. Panel C depicts data representing multisensory TBWs across a range of stimuli similar to Panel A. Individuals with ASD showed wider TBWs only with speech stimuli. Panel B shows data from these same participants exhibiting a decrease in the McGurk effect. Importantly, Panel E displays the relationships between TBWs and the McGurk effect, showing that decreased multisensory temporal acuity in ASD was associated with weaker multisensory integration of speech signals. Panels C-E are adapted from Stevenson et al. [2014a] error bars represent standard error.

$320 \mathrm{~ms}$ to measure just-noticeable differences. Individuals with ASD demonstrated diminished multisensory temporal order sensitivity across stimulus types, from simple flashes and beeps to speech stimuli (Fig. 3A) [de Boer-Schellekens et al., 2013]. Whereas previous studies showed that individuals with ASD bind stimuli at wider 
SOAs [Foss-Feig et al., 2010; Kwakye et al., 2011; Woynaroski et al., 2013], this provides complementary evidence by demonstrating that individuals with ASD were also less able to disambiguate the temporal order of multisensory stimuli.

Similar to the study by de Boer-Schellekens and colleagues [2013], a recent study investigated the ability of individuals with ASD to bind multisensory inputs across a range of different stimulus categories in a single cohort of individuals [Stevenson, Siemann, et al., 2014]. Participants (6-18 years old, mean verbal IQ $t$-scores $=56$, no report of language proficiency) were presented with simple flashes and beeps, simple nonspeech stimuli (hammers hitting a substrate), and simple speech stimuli (single-syllable utterances). Participants performed a simultaneity judgment task, with trial presentations parametrically varied from $400 \mathrm{~ms}$ auditory leading to $400 \mathrm{~ms}$ visual leading. From these judgments, TBWs were measured for each individual and for each stimulus type. Similar to the results from the original Bebko et al. [2006] preferential looking paradigm, Stevenson and colleagues found atypical multisensory temporal processing only for speech stimuli, and no group differences for the simple or more complex nonspeech stimuli (Fig. 3C). These results, however, differ from the de BoerSchellekens et al. study that not only found group differences with speech stimuli, but also found group differences in simple and complex nonspeech stimuli. Although somewhat surprising, these disparate findings can be reconciled if the temporal order judgment task and the simultaneity judgment task access distinct cognitive processes and/or mechanisms [Vroomen \& Keetels, 2010], a dissociation supported by evidence that these two tasks are relatively uncorrelated within subjects [Hirsh \& Sherrick, 1961; Stevenson \& Wallace, 2013; van Eijk, Kohlrausch, Juola, \& van de Par, 2008; Vatakis, Navarra, Soto-Faraco, \& Spence, 2008].

In addition to the battery of tests assessing temporal processing, Stevenson, Siemann, et al. [2014] also administered a McGurk paradigm with synchronous presentations (Fig. 3D). As previously mentioned, in TD populations, individual differences in TBW width has been shown to be predictive of the magnitude of individuals' audiovisual integration as indexed by the McGurk Effect [Stevenson, Zemtsov, et al., 2012]. By the same token, individuals with ASD that showed less precise temporal processing with speech stimuli also showed reduced McGurk susceptibility, with a striking correlation $(R=0.67)$ between the width of the TBW with speech stimuli and susceptibility to the McGurk Effect. In addition, and perhaps of greatest interest, the TBW width of individuals with ASD as measured using nonspeech stimuli, which did not differ from the TD control group, was significantly correlated with susceptibility to the McGurk Effect in children with ASD
(Fig. 3E). Hence, even the multisensory temporal binding of the lowest-level stimuli (i.e. simple flashes and beeps) was significantly correlated with individuals' perceptual fusion of audiovisual speech, suggesting some common mechanistic underpinnings to these processes. With that said, while the McGurk Effect is used here as a proxy for speech integration, measures using integration on the whole-word or sentence level of speech perception would provide valuable advances in this line of work.

\section{Examination of Autism Traits in the General Population}

An emerging direction of research with strong clinical relevance examines autism and autistic traits as they relate to the broader population. As a spectrum disorder, symptoms of autism are found to varying degrees in the population of children with ASD at large. In addition, these symptoms are seen to varying degrees in members of the general population who fail to meet criteria for an autism diagnosis, and can be indexed using measures such as the Autism Quotient [BaronCohen, Wheelwright, Skinner, Martin, \& Clubley, 2001] or the Broad Autism Phenotype Questionnaire [Hurley, Losh, Parlier, Reznick, \& Piven, 2007].

To date, a single study has broached the topic of how autism symptoms in the broader population relate to multisensory temporal processes [Donohue, Darling, \& Mitroff, 2012]. In this study, TD university students $(N=104$, mean age $=21.4$, range not reported $)$ completed a simultaneity judgment task while being presented with visual flashes and auditory beeps, with SOAs ranging from $300 \mathrm{~ms}$ visual leading to $300 \mathrm{~ms}$ audio leading. Performance on this task was then related to traits commonly observed in autism using the Autism Quotient. Donohue and colleagues' main measure of interest was the point of subjective simultaneity, the SOA at which a participant most likely perceived synchrony. Indeed, prior work has shown that the SOA at which the probability of simultaneity judgments peaks is often asymmetrical and typically is seen when the auditory signal slightly lags the visual signal, reflecting the statistics of the natural environment [Dixon \& Spitz, 1980; Meredith et al., 1987; Roach, Heron, Whitaker, \& McGraw, 2011; Seitz, Nanez, Holloway, \& Watanabe, 2006; Zampini, Guest, et al., 2005; Zampini, Shore, \& Spence, 2003, 2005]. In contrast to this visual-leading asymmetry in TD individuals [van Eijk et al., 2008], Donohue and colleagues found the reverse in individuals who had higher degrees of autism-like traits (Fig. 3B). One interpretation of this finding is that individuals in the general population with a greater (yet nonclinical) number of autistic-like 


\section{A. Typical Development of the TBW}

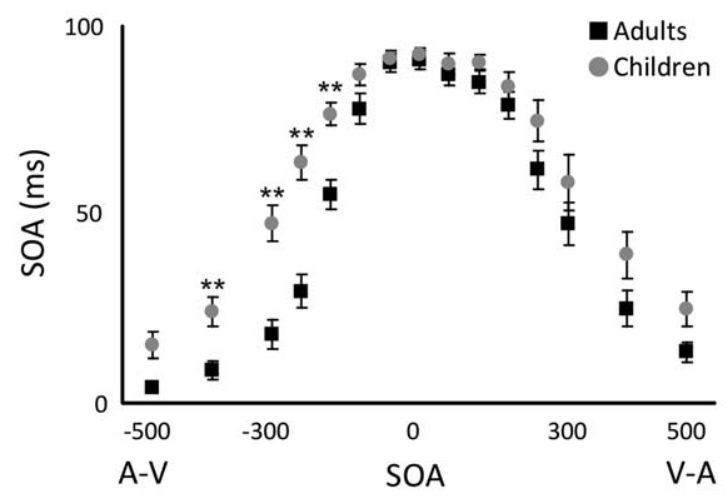

C. Plasticity of the TBW via Perceptual Learning

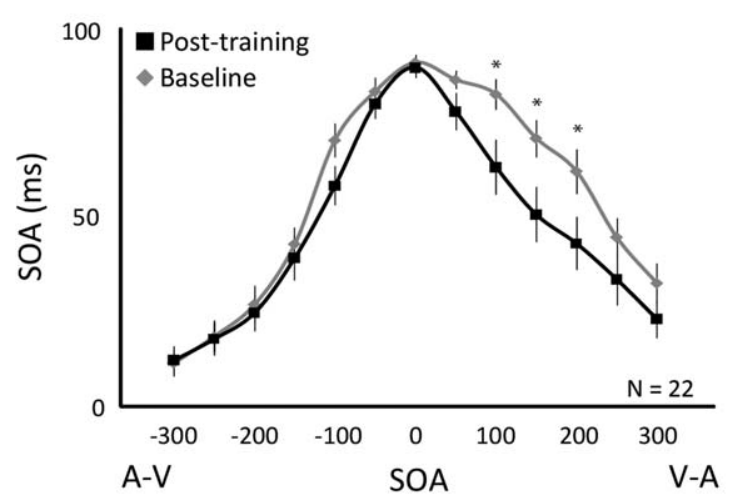

B. Modulating the TBW

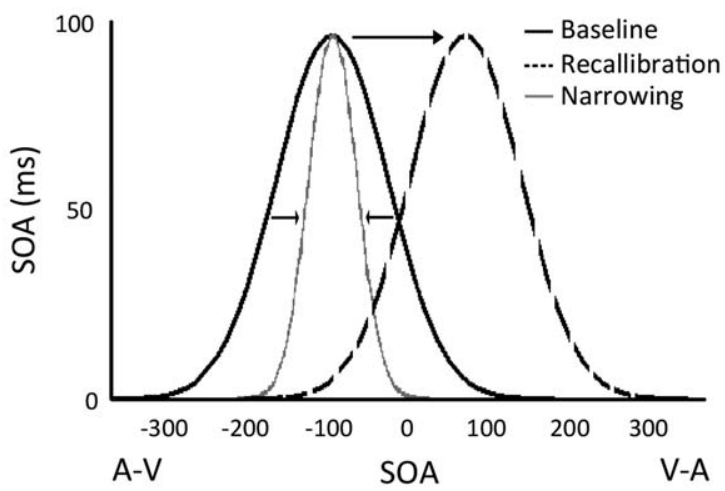

D. Initial TBW Width and Training Effect

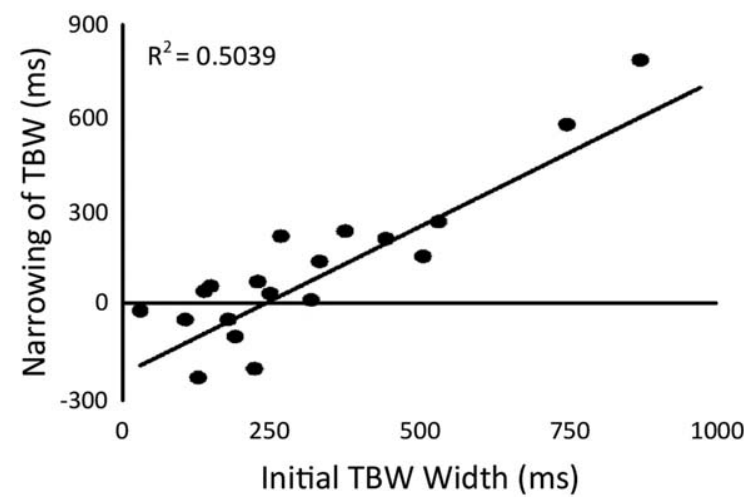

Figure 4. Plasticity of the multisensory TBW. Panel A shows average changes in the TBW through development, where a significant narrowing of the left side of the TBW takes place early in development followed by a later, smaller narrowing of the right side later in development [adapted from Hillock-Dunn \& Wallace, 2012]. Error bars represent standard error. Panel B depicts two types of malleability that have been experimentally induced, including recalibration, or a shifting of the entire TBW, and narrowing, or a reduction in the width of the window. This suggests that even the mature TBW is still malleable. Panel $C$ is an example of perceptual narrowing seen in a multisensory perceptual training study in which multisensory temporal acuity improved over the course of the experiment. Panel $D$ shows that the effectiveness of this training paradigm correlated with the initial width of the TBW, such that individuals with less multisensory temporal acuity showed a greater increase in acuity with training. Panels C and D are adapted from Powers et al. [2009] error bars represent standard error.

traits have sensory systems that are less adaptive to the temporal statistics of the environment [Pellicano \& Burr, 2012; Sinha et al., 2014; van Boxtel \& Lu, 2013; Van de Cruys et al., 2014].

Perhaps the most common theme in the experiments discussed to this point is that individuals with ASD show multisensory interactions across a wider temporal window than do TD individuals. In many ways, this enlarged window matches that of an immature TBW. Infants exhibit a window of integration that is wider and more symmetrical than a mature TBW [Lewkowicz, 1996, 2000; Lewkowicz \& Ghazanfar, 2009; Lewkowicz \& Lickliter, 2013]. The first developmental change observed is a narrowing of the left side of the window (Fig. 4A), representing a restriction of tolerance for auditory-leading sensory inputs, a temporal relationship that is not generally found in the natural environment. Following this, the right side of the window, reflecting visual-leading sensory inputs, slowly narrows throughout adolescence, but to a lesser degree than the left side of the window [Hillock et al., 2011; Hillock-Dunn \& Wallace, 2012]. Collectively, these maturational processes build a TBW that is highly asymmetrical [Conrey \& Pisoni, 2006; Dixon \& Spitz, 1980; Hillock et al., 2011; Stevenson et al., 2010; van Atteveldt et al., 2007; van Wassenhove et al., 2007; Vroomen \& Keetels, 2010]. The findings that individuals with ASD show broader and more symmetrical TBWs, suggest a failure of the perceptual system to adapt to the statistical characteristics of the external environment, and thus a preservation of a TBW that appears immature.

Multisensory Integration in Theories of ASD

Most recent theoretical accounts of ASD include aspects that are applicable to the decreases in multisensory 
integration observed in ASD. Two relevant theories focus on the processing level toward which individuals with ASD focus, Weak Central Coherence [Frith \& Happe, 1994] and the Enhanced Perceptual Functioning Model of ASD [Mottron, Dawson, Soulieres, Hubert, \& Burack, 2006]. Weak Central Coherence suggests that individuals with ASD lose the proverbial forest for the sake of the trees in that their default processing is geared toward details at the expense of the gestalt whole. Phrased in terms of multisensory processing, this could be interpreted as focusing on the unisensory components at the expense of creating a perceptually bound, multisensory percept. The Enhanced Perceptual Functioning Model of ASD is more specific in terms of sensory perception, suggesting that individuals with ASD show enhanced low-level perception of visual and auditory inputs, but diminished performance in more complex sensory perception, such as multisensory perception. Despite these specific applications to multisensory perception, neither theory is directly applicable to temporal perception.

Two theories of ASD that are directly relevant to temporal multisensory perception in ASD are the Temporal Binding Hypothesis [Brock et al., 2002] and the Predictive Coding Hypothesis [Pellicano \& Burr, 2012]. The Temporal Binding Hypothesis suggests that neural firing patterns in the Autistic brain are less temporally reliable. Thus, in systems in which two incoming action potentials would converge upon a single neuron, or clusters of neurons are required to fire synchronously, individuals with ASD will show deficits. Sensory integration is one such process, where auditory and visual processing streams must inherently converge. If temporal reliability of such signals is decreased, the natural result of this would be a deficit in multisensory temporal precision. The Predictive Coding Hypothesis is a Bayesian account of autism, suggesting that individuals with ASD have a decreased ability to learn the statistics of their environment. Multisensory temporal perception is an inherently developmental process in which an individual must learn from the statistics of the environment that sensory inputs that are temporally synchronous and share similar temporal dynamics, also originate from the same event. If statistical learning is impacted, so too will be multisensory temporal precision.

\section{The Neurobiological Bases for Altered Multisensory} Temporal Function in ASD

While there is an entire network of brain regions subserving multisensory temporal function, the posterior superior temporal cortex (pSTS) is one region that shows a clear overlap with ASD. Posterior STS has been well characterized in terms of its role in multisensory processing [Andersen \& Buneo, 2002; Bremmer, 2005, 2011; Bushara, Grafman, \& Hallett, 2001; Calvert, Campbell, \& Brammer, 2000; Herdener et al., 2009; James \& Stevenson, 2012; James, Stevenson, \& Kim, 2012; James, VanDerKlok, Stevenson, \& James, 2011; Pasalar, Ro, \& Beauchamp, 2010; Puce, Epling, Thompson, \& Carrick, 2007; Schlack, Sterbing-D'Angelo, Hartung, Hoffmann, \& Bremmer, 2005; Soto-Faraco, Kingstone, \& Spence, 2006; van Atteveldt, Blau, Blomert, \& Goebel, 2010; van Atteveldt et al., 2007]. In addition, the pSTS appears to play a role in encoding the temporal structure of multisensory events, being differentially active for synchronous relative to asynchronous audiovisual presentations [Beauchamp, Yasar, Frye, \& Ro, 2008; Bushara et al., 2001; Lewis \& Noppeney, 2010; Macaluso et al., 2004; Stevenson et al., 2010, 2011]. Furthermore, the pSTS is also well known for its role in audiovisual speech processing [Bishop \& Miller, 2009; Calvert et al., 2000; Nath \& Beauchamp, 2011; Stevenson \& James, 2009; Stevenson, Kim, \& James, 2009; Stevenson et al., 2010, 2011], including playing a central role in the perception of the McGurk effect [Beauchamp, Nath, \& Pasalar, 2010; Nath \& Beauchamp, 2011, 2012; Nath, Fava, \& Beauchamp, 2011; Sekiyama, Kanno, Miura, \& Sugita, 2003]. A causal role for the pSTS in multisensory integration was demonstrated in a recent transcranial magnetic stimulation (TMS) study, which showed that TMS over the pSTS resulted in a significant reduction in the perceptual binding of audiovisual speech as indexed by the McGurk Effect [Beauchamp et al., 2010].

In addition to being a clear locus for multisensory integration and binding, as well as one that is highly sensitive to the temporal structure of multisensory cues, the pSTS is also altered in ASD. More specifically, the pSTS is known to differ structurally between individuals with and without ASD [Boddaert \& Zilbovicius, 2002; Boddaert, Chabane, Gervais, et al., 2004; Boddaert et al., 2009; Brunelle, Boddaert, \& Zilbovicius, 2009; Levitt et al., 2003] in both gray matter volume [Boddaert, Chabane, Gervais, et al., 2004], gyrations [Levitt et al., 2003], and white matter connectivity [Boddaert, Chabane, Gervais, et al., 2004; Conturo et al., 2008; Lange et al., 2010; Lee et al., 2007]. Posterior STS also showed differential activation patterns with audiovisual speech stimuli and complex sounds in individuals with ASD relative to their TD peers [Boddaert \& Zilbovicius, 2002; Brunelle et al., 2009; Boddaert et al., 2003; Boddaert, Chabane, Belin, et al., 2004; Pelphrey \& Carter, 2008a,b; Redcay \& Courchesne, 2008; Zilbovicius et al., 2000; Zilbovicius, Meresse, \& Boddaert, 2006; Zilbovicius, Meresse, Chabane, et al., 2006]. Finally, pSTS has been functionally linked to a wide array of other cognitive processes known to be impaired in ASD, including, but not limited to, processing of social 
stimuli, biological motion, face processing, and theory of mind [for review, see Hein \& Knight, 2008].

In addition to differential brain activation in ASD, weaker effective connectivity between pSTS and a wide range of other brain regions has been shown in ASD [Alaerts et al., 2014; Just, Cherkassky, Keller, \& Minshew, 2004; Koshino et al., 2005, 2008; Shih et al., 2011]. Furthermore, functional connectivity changes in pSTS of individuals with ASD have been shown to predict behavioral symptomology, such as emotion recognition [Alaerts et al., 2014]. These findings of functional connectivity differences in ASD are complemented by findings of weaker anatomical connectivity between brain regions as indexed by diffusion tensor imaging. These studies also suggest that pSTS in particular is a site of interest in ASD, again showing more diffuse white matter tracts connecting pSTS with a range of other brain regions [Boddaert, Chabane, Gervais, et al., 2004; Conturo et al., 2008; Lange et al., 2010; Lee et al., 2007].

\section{Consequences of Altered Multisensory Temporal Function and Possibilities for Remediation}

The perceptual differences in multisensory temporal processing observed in ASD have significant effects that extend beyond perceptual systems. Simply stated, sensory and multisensory systems form the building blocks upon which higher-order representations are constructed. Hence, it is reasonable that deviations from typical (multi)sensory function, like those seen in ASD, will have powerful cascading impacts on higher-order domains such as speech communication [Stevenson, Segers, et al., 2014]. At the same time, these perceptualcognitive links may also represent a possible useful tool that can be harnessed for remediation. Multisensory temporal processing is not an immutable characteristic of an individual, but is in fact quite dynamic. Highlighting this dynamism, multisensory temporal perception has been shown to be malleable via two forms of perceptual learning (Fig. 4B), bottom-up recalibration through exposure [Fujisaki, Shimojo, Kashino, \& Nishida, 2004; Harrar \& Harris, 2008; Keetels \& Vroomen, 2008; Miyazaki, Yamamoto, Uchida, \& Kitazawa, 2006; Navarra et al., 2005; Vatakis et al., 2008; Vroomen, Keetels, de Gelder, \& Bertelson, 2004], and top-down feedback training [Powers et al., 2009; Powers, Hevey, \& Wallace, 2012; Schlesinger, Stevenson, Shotwell, \& Wallace, 2014; Stevenson et al., 2013]. These latter studies have focused specifically on the TBW. Following a brief period of training in which individuals were given performancebased feedback on their simultaneity judgments (a sametime or different-time perceptual task), a significant narrowing of the TBW was observed (Fig. 4C) [Powers et al., 2009]. To date, these studies have only been carried out in typically developing individuals. Given the associa- tion between width of the TBW and sensory integration abilities observed in both TD [Stevenson, Zemstov, et al., 2012] and ASD [Stevenson, Seimann, et al., 2014], it has been proposed that narrowing of the TBW in participants with ASD may have a cascading effect on higherorder cognitive and social domains.

While the implementation of perceptual-learning paradigms in populations with ASD is in its infancy, there is reason to believe that these training regiments may be effective in this group. The individuals with TD who began training with imprecise multisensory temporal processing, including those with TBWs similar to those seen in ASD, showed the most change with training (Fig. 4D) [Powers et al., 2009]. Thus, it is conceivable that individuals with ASD may benefit from such training. Particularly, germane to adapting this training regime for use in ASD, the changes observed were rapid (seen after one day), long lasting (enduring for several weeks), dependent upon feedback (and not simply passive exposure), and were not a result of shifts in response bias. Perhaps most important is evidence that the effects generalized to domains beyond those trained. More specifically, training on a simultaneity judgment task using simple low-level stimuli have resulted in performance changes across different tasks using similar stimuli, as well as in tasks using more complex stimuli (i.e. the McGurk Effect). The presence of generalization in TD populations is critical in that it suggests that training may be capable of driving multisensory processing improvements in individuals with ASD, and that these improvements may cascade into higher order cognitive domains (i.e. communication, social interactions) that are core weaknesses in autism. Again, it should be noted here that implementation of this remediation is in its infancy, and more work needs to be done to test the feasibility of such training in populations with ASD.

The results of these plasticity studies have been shown not only behaviorally, but also neurally. To investigate the brain regions most affected by multisensory perceptual training, Powers and colleagues [2012] performed an fMRI study subsequent to their behavioral study. Not surprisingly, one brain region showing substantive changes in activity and connectivity was the pSTS (Fig. 5). Somewhat counterintuitively, the training-related effects described above that resulted in a narrowing of the multisensory TBW resulted in decreases in blood-oxygenated level dependent response to objectively simultaneous and highly asynchronous conditions, suggesting that the changes may reflect an increased efficiency of processing [Grill-Spector, Henson, \& Martin, 2006; Murray \& Spierer, 2009; Schiltz et al., 1999; Stevenson, Bushmakin, et al., 2012; Stevenson et al., 2010; Stevenson et al., 2011]. On top of that, analyses of effective and resting state connectivity showed that the training regime from Powers et al. 


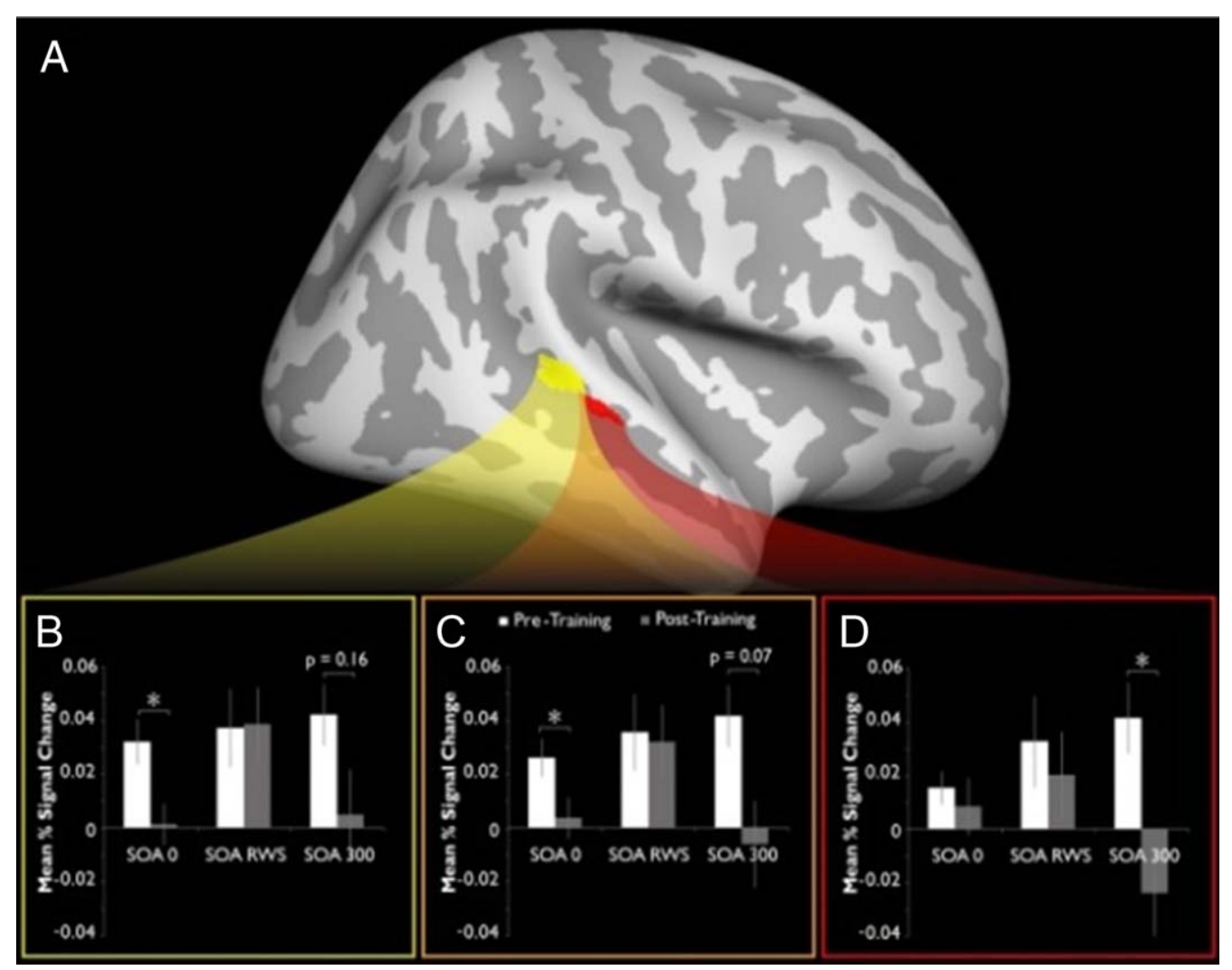

Figure 5. Neural plasticity related to multisensory temporal processing. Changes in neural activity associated with multisensory temporal perceptual learning were localized to the posterior temporal sulcus (pSTS; Panel A). Within pSTS, decreases in activity following training were seen for trials that were either exactly synchronous (SOA 0) or widely disparate (SOA 300), reflecting an increased efficiency of processing. Presentations at individuals' perceptual threshold (SOA RWS), however, showed no change in activation (Panels B-D). Error bars represent standard error. Panels A-D are adapted from Powers et al. [2012].

[2012] resulted in significant changes in the connectivity between pSTS and a network of areas including visual and auditory cortex, reflecting known differences between in connectivity between populations with and without ASD [Boddaert, Chabane, Gervais, et al., 2004; Conturo et al., 2008; Just et al., 2004; Koshino et al., 2005, 2008; Lange et al., 2010; Lee et al., 2007].

Taken together, these results suggest that multisensory temporal training and the associated neural substrates, may represent a possible target for future remediation studies. In addition to the possibility that such training might "normalize" sensory and multisensory function, there is also the possibility that such training may have effects on perceptual, social, and cognitive domains, each of which are dependent upon the integrity of the information that they receive from the sensory streams.

\section{Future Directions}

There are a number of pertinent directions that future research must explore, over and above in addition to the proposed remediation strategy, before we have a solid grasp on the issues underlying the differences in multisensory integration in ASD. First, there is a dearth of research investigating the neural underpinnings of the differences in multisensory perception in ASD and TD. While even this basic research is lacking, investigating the neural links between sensory dysfunction and the impact it has on higher-level cognitive processing will also allow us to map changes in sensory perception with the more classic symptomology of ASD. In this light, there is also a great need for investigation into the impact that changes in sensory perception have on cognitive functioning in ASD behaviorally. For example, do changes in multisensory integration impact how an individual with ASD perceives facial expressions of affect and emotional prosody in speech? A developmental trajectory approach is sorely needed to address, in a longitudinal fashion, how differences in multisensory integration develop (or fail to) in individuals in ASD, and whether sensory differences in infancy do in fact have cascading impacts on downstream cognitive development. Finally, this work has in all cases been conducted in populations of high-functioning children with ASD, and although methodologically difficult, 
should be extended into lower-functioning and nonverbal groups.

\section{Conclusions}

Sensory and multisensory integration are critical processes for dealing with the vast amount of sensory information we encounter at any given time. This information must be assembled rapidly into a coherent perceptual gestalt of our world. This process is dependent upon the timing of the respective inputs, as this information is a key determinant in assessing whether two sensory inputs should be perceptually integrated. In individuals with ASD, multisensory temporal perception differs from those without ASD, and this difference in temporal processing leads to atypical sensory integration, which possibly cascades into higher-order issues such as communicative and social impairments. A difference in multisensory temporal processing also provides a possible means for remediation, as this process has shown to be remarkably malleable not only through development but also in response to experience and perceptual learning. As such, the investigation of multisensory temporal processing in ASD, its relation to the higher-order clinical symptomology of ASD, and its use as a remediation tool are all areas of inquiry that deserve additional focus.

\section{Acknowledgments}

Support for this work for R.S. came from a Banting Postdoctoral Fellowship granted by the Canadian Natural Sciences and Engineering Research Council (NSERC), The Autism Research Training Program funded by The Canadian Institutes of Health Research (CIHR), and an NRSA fellowship from the American NIH's National Institute of Deafness and Communicative Disorders (NIDCD 1F32 DC011993). Support for M.B. comes from a Scholar Award from the James S. McDonnell Foundation and CIHR (MOP-115148). This work was also supported by a NSERC Grant (216203-13) and CIHR Grant (106436) to S.F., and a Simons Foundation Explorer Award to M.W.

\section{References}

ADDM. (2014). Prevalence of autism spectrum disorder among children aged 8 years - Autism and developmental disabilities monitoring network, 11 sites, United States, 2010. Morbidity and Mortality Weekly Report Surveillance Summaries, 63, 1-21.

Alaerts, K., Woolley, D.G., Steyaert, J., Di Martino, A., Swinnen, S.P., \& Wenderoth, N. (2014). Underconnectivity of the superior temporal sulcus predicts emotion recognition deficits in autism. Social Cognitive and Affective Neuroscience, 9, 1589-1600.
Andersen, R.A., \& Buneo, C.A. (2002). Intentional maps in posterior parietal cortex. Annual Review of Neuroscience, 25, 189-220.

APA. (2013). Diagnostic and statistical manual of mental disorders: DSM-5 (5th ed.). Arlington, VA: American Psychiatric Association.

Baio, J. (2012). Prevalence of autism spectrum disorders: Autism and developmental disabilities monitoring network, 14 sites, United States, 2008. Morbidity and mortality weekly report. Surveillance summaries (Vol. 61, Number 3). Centers for Disease Control and Prevention.

Baranek, G.T., David, F.J., Poe, M.D., Stone, W.L., \& Watson, L.R. (2006). Sensory experiences questionnaire: Discriminating sensory features in young children with autism, developmental delays, and typical development. Journal of Child Psychology and Psychiatry, 47, 591-601.

Baron-Cohen, S., Wheelwright, S., Skinner, R., Martin, J., \& Clubley, E. (2001). The autism-spectrum quotient (aq): Evidence from asperger syndrome/high-functioning autism, malesand females, scientists and mathematicians. Journal of Autism and Developmental Disorders, 31, 5-17.

Beauchamp, M.S., Nath, A.R., \& Pasalar, S. (2010). fMRI-guided transcranial magnetic stimulation reveals that the superior temporal sulcus is a cortical locus of the Mcgurk effect. Journal of Neuroscience, 30, 2414-2417.

Beauchamp, M.S., Yasar, N.E., Frye, R.E., \& Ro, T. (2008). Touch, sound and vision in human superior temporal sulcus. NeuroImage, 41, 1011-1020.

Baum, S.H., Stevenson, R.A., \& Wallace, M.T. (In Press). Behavioral, perceptual, and neural alterations in sensory and multisensory function in autism spectrum disorder. Progress in Neurobiology, DOI:10.1016/j.pneurobio.2015.09.007.

Bebko, J.M., Schroeder, J.H., \& Weiss, J.A. (2014). The Mcgurk effect in children with autism and Asperger syndrome. Autism Research, 7, 50-59.

Bebko, J.M., Weiss, J.A., Demark, J.L., \& Gomez, P. (2006). Discrimination of temporal synchrony in intermodal events by children with autism and children with developmental disabilities without autism. Journal of Child Psychology and Psychiatry, 47, 88-98.

Bertone, A., Mottron, L., Jelenic, P., \& Faubert, J. (2005). Enhanced and diminished visuo-spatial information processing in autism depends on stimulus complexity. Brain, 128, 2430-2441.

Bishop, C.W., \& Miller, L.M. (2009). A multisensory cortical network for understanding speech in noise. Journal of Cognitive Neuroscience, 21, 1790-1805.

Boddaert, N., Belin, P., Chabane, N., Poline, J.B., Barthelemy, C., Mouren-Simeoni, M.C., ... Zilbovicius, M. (2003). Perception of complex sounds: Abnormal pattern of cortical activation in autism. The American Journal of Psychiatry, 160, 2057-2060.

Boddaert, N., Chabane, N., Belin, P., Bourgeois, M., Royer, V., Barthelemy, C., ... Zilbovicius, M. (2004). Perception of complex sounds in autism: Abnormal auditory cortical processing in children. The American Journal of Psychiatry, 161, 2117-2120.

Boddaert, N., Chabane, N., Gervais, H., Good, C.D., Bourgeois, M., Plumet, M.H., ... Zilbovicius, M. (2004). Superior temporal sulcus anatomical abnormalities in childhood autism: 
A voxel-based morphometry mri study. NeuroImage, 23, 364-369.

Boddaert, N., \& Zilbovicius, M. (2002). Functional neuroimaging and childhood autism. Pediatric Radiology, 32, 1-7.

Boddaert, N., Zilbovicius, M., Philipe, A., Robel, L., Bourgeois, M., Barthelemy, C., ... Chabane, N. (2009). Mri findings in 77 children with non-syndromic autistic disorder. PLoS One, 4, e4415.

Bolognini, N., Frassinetti, F., Serino, A., \& Ladavas, E. (2005). "Acoustical vision" of below threshold stimuli: Interaction among spatially converging audiovisual inputs. Experimental Brain Research [Experimentelle Hirnforschung], 160, 273-282.

Brandwein, A.B., Foxe, J.J., Butler, J.S., Russo, N.N., Altschuler, T.S., Gomes, H., \& Molholm, S. (2012). The development of multisensory integration in high-functioning autism: Highdensity electrical mapping and psychophysical measures reveal impairments in the processing of audiovisual inputs. Cerebral Cortex, bhs109.

Bremmer, F. (2005). Navigation in space-The role of the macaque ventral intraparietal area. The Journal of Physiology, 566, 29-35.

Bremmer, F. (2011). Multisensory space: From eye-movements to self-motion. The Journal of Physiology, 589, 815-823.

Brock, J., Brown, C.C., Boucher, J., \& Rippon, G. (2002). The temporal binding deficit hypothesis of autism. Development and Psychopathology, 14, 209-224.

Brunelle, F., Boddaert, N., \& Zilbovicius, M. (2009). [Autism and brain imaging]. Bulletin de l'Académie nationale de médecine, 193, 287-297 [discussion 297-288].

Bushara, K.O., Grafman, J., \& Hallett, M. (2001). Neural correlates of auditory-visual stimulus onset asynchrony detection. Journal of Neuroscience, 21, 300-304.

Calvert, G.A., Campbell, R., \& Brammer, M.J. (2000). Evidence from functional magnetic resonance imaging of crossmodal binding in the human heteromodal cortex. Current Biology, 10, 649-657.

Cardy, J.E.O., Flagg, E.J., Roberts, W., Brian, J., \& Roberts, T.P. (2005). Magnetoencephalography identifies rapid temporal processing deficit in autism and language impairment. Neuroreport, 16, 329-332.

Cascio, C.J., Foss-Feig, J.H., Burnette, C.P., Heacock, J.L., \& Cosby, A.A. (2012). The rubber hand illusion in children with autism spectrum disorders: Delayed influence of combined tactile and visual input on proprioception. Autism, $16,406-419$.

Collignon, O., Charbonneau, G., Peters, F., Nassim, M., Lassonde, M., Lepore, F., ... Bertone, A. (2013). Reduced multisensory facilitation in persons with autism. Cortex: A Journal Devoted to the Study of the Nervous System and Behavior, 49, 1704-1710.

Colonius, H., \& Diederich, A. (2004). Multisensory interaction in saccadic reaction time: A time-window-of-integration model. Journal of Cognitive Neuroscience, 16, 1000-1009.

Conrey, B., \& Pisoni, D.B. (2006). Auditory-visual speech perception and synchrony detection for speech and nonspeech signals. The Journal of the Acoustical Society of America, 119, 4065-4073.

Conturo, T.E., Williams, D.L., Smith, C.D., Gultepe, E., Akbudak, E., \& Minshew, N.J. (2008). Neuronal fiber path- way abnormalities in autism: An initial MRI diffusion tensor tracking study of hippocampo-fusiform and amygdalo-fusiform pathways. Journal of the International Neuropsychological Society, 14, 933-946.

Corey, D.P., \& Hudspeth, A.J. (1979). Response latency of vertebrate hair cells. Biophysical Journal, 26, 499-506.

Dawson, G., \& Watling, R. (2000). Interventions to facilitate auditory, visual, and motor integration in autism: A review of the evidence. Journal of Autism and Developmental Disorders, 30, 415-421.

de Boer-Schellekens, L., Eussen, M., \& Vroomen, J. (2013). Diminished sensitivity of audiovisual temporal order in autism spectrum disorder. Frontiers in Integrative Neuroscience, 7,8 .

de Gelder, B., Vroomen, J., \& Van der Heide, L. (1991). Face recognition and lip-reading in autism. European Journal of Cognitive Psychology, 3, 69-86.

Diederich, A., \& Colonius, H. (2004). Bimodal and trimodal multisensory enhancement: Effects of stimulus onset and intensity on reaction time. Perception \& Psychophysics, 66, 1388-1404.

Dixon, N.F., \& Spitz, L. (1980). The detection of auditory visual desynchrony. Perception, 9, 719-721.

Donohue, S.E., Darling, E.F., \& Mitroff, S.R. (2012). Links between multisensory processing and autism. Experimental Brain Research, 222, 377-387.

Foss-Feig, J.H., Kwakye, L.D., Cascio, C.J., Burnette, C.P., Kadivar, H., Stone, W.L., \& Wallace, M.T. (2010). An extended multisensory temporal binding window in autism spectrum disorders. Experimental Brain Research [Experimentelle Hirnforschung], 203, 381-389.

Frith, U., \& Happe, F. (1994). Autism: Beyond "theory of mind". Cognition, 50, 115-132.

Fujisaki, W., Shimojo, S., Kashino, M., \& Nishida, S.Y. (2004). Recalibration of audiovisual simultaneity. Nature Neuroscience, 7, 773-778.

Gondan, M., Niederhaus, B., Rosler, F., \& Roder, B. (2005). Multisensory processing in the redundant-target effect: A behavioral and event-related potential study. Perception \& Psychophysics, 67, 713-726.

Grill-Spector, K., Henson, R., \& Martin, A. (2006). Repetition and the brain: Neural models of stimulus-specific effects. Trends in Cognitive Science, 10, 14-23.

Grossman, R.B., Schneps, M.H., \& Tager-Flusberg, H. (2009). Slipped lips: Onset asynchrony detection of auditory-visual language in autism. Journal of Child Psychology and Psychiatry, 50, 491-497.

Grossman, R.B., Steinhart, E., Mitchell, T., \& Mcllvane, W. (2015). "Look who's talking!" gaze patterns for implicit and explicit audio-visual speech synchrony detection in children with high-functioning autism. Autism Research, 8, 307-316.

Hairston, W.D., Burdette, J.H., Flowers, D.L., Wood, F.B., \& Wallace, M.T. (2005). Altered temporal profile of visualauditory multisensory interactions in dyslexia. Experimental Brain Research [Experimentelle Hirnforschung], 166, $474-480$.

Hairston, W.D., Hodges, D.A., Burdette, J.H., \& Wallace, M.T. (2006). Auditory enhancement of visual temporal order judgment. Neuroreport, 17, 791-795. 
Harrar, V., \& Harris, L.R. (2008). The effect of exposure to asynchronous audio, visual, and tactile stimulus combinations on the perception of simultaneity. Experimental Brain Research, 186, 517-524.

Hein, G., \& Knight, R.T. (2008). Superior temporal sulcus-It's my area: Or is it? Journal of Cognitive Neuroscience, 20 2125-2136.

Herdener, M., Lehmann, C., Esposito, F., di Salle, F., Federspiel, A., Bach, D.R., ... Seifritz, E. (2009). Brain responses to auditory and visual stimulus offset: Shared representations of temporal edges. Human Brain Mapping, 30, 725-733.

Hershenson, M. (1962). Reaction time as a measure of intersensory facilitation. Journal of Experimental Psychology, 63, 289-293.

Hillock, A.R., Powers, A.R., \& Wallace, M.T. (2011). Binding of sights and sounds: Age-related changes in multisensory temporal processing. Neuropsychologia, 49, 461-467.

Hillock-Dunn, A., \& Wallace, M.T. (2012). Developmental changes in the multisensory temporal binding window persist into adolescence. Developmental Science, 15, 688-696.

Hirsh, I.J., \& Sherrick, C.E. Jr. (1961). Perceived order in different sense modalities. Journal of Experimental Psychology, 62, 423-432.

Hughes, H.C., Reuter-Lorenz, P.A., Nozawa, G., \& Fendrich, R. (1994). Visual-auditory interactions in sensorimotor processing: Saccades versus manual responses. Journal of Experimanetal Psychology: Human Perception and Performance, 20, 131-153.

Hurley, R.S., Losh, M., Parlier, M., Reznick, J.S., \& Piven, J. (2007). The broad autism phenotype questionnaire. Journal of Autism and Developmental Disorders, 37, 1679-1690.

Iarocci, G., Rombough, A., Yager, J., Weeks, D.J., \& Chua, R. (2010). Visual influences on speech perception in children with autism. Autism, 14, 305-320.

Irwin, J.R., Tornatore, L.A., Brancazio, L., \& Whalen, D.H. (2011). Can children with autism spectrum disorders "hear" a speaking face? Child Development, 82, 1397-1403.

James, T.W., \& Stevenson, R.A. (2012). The use of fMRI to assess multisensory integration. In M.H. Wallace \& M.M. Murray (Eds.), Frontiers in the neural basis of multisensory processes. London: Taylor \& Francis.

James, T.W., Stevenson, R.A., \& Kim, S. (2012). Inverse effectiveness in multisensory processing. In B E. Stein (Ed.), The new handbook of multisensory processes. Cambridge, MA: MIT Press.

James, T.W., VanDerKlok, R.M., Stevenson, R.A., \& James, K.H. (2011). Multisensory perception of action in posterior temporal and parietal cortices. Neuropsychologia, 49, 108-114.

Just, M.A., Cherkassky, V.L., Keller, T.A., \& Minshew, N.J. (2004). Cortical activation and synchronization during sentence comprehension in high-functioning autism: Evidence of underconnectivity. Brain, 127, 1811-1821.

Kanner, L. (1943). Autistic disturbances of affective contact. The Nervous Child, 2, 217-250.

Kasari, C., \& Sigman, M. (1997). Linking parental perceptions to interactions in young children with autism. Journal of Autism and Developmental Disorders, 27, 39-57.

Keane, B.P., Rosenthal, O., Chun, H.N., \& Shams, L. (2010). Audiovisual integration in high functioning adults with autism. Research in Autism Spectrum Disorders, 4, 276-289.
Keetels, M., \& Vroomen, J. (2005). The role of spatial disparity and hemifields in audio-visual temporal order judgments. Experimental Brain Research [Experimentelle Hirnforschung], 167, 635-640.

Keetels, M., \& Vroomen, J. (2008). Temporal recalibration to tactile-visual asynchronous stimuli. Neuroscience Letters, 430, 130-134.

Kern, J.K., Trivedi, M.H., Grannemann, B.D., Garver, C.R., Johnson, D.G., Andrews, A.A., ... Schroeder, J.L. (2007). Sensory correlations in autism. Autism, 11, 123-134.

Kientz, M.A., \& Dunn, W. (1997). A comparison of the performance of children with and without autism on the sensory profile. The American Journal of Occupational Therapy, 51, 530-537.

King, A.J., \& Palmer, A.R. (1985). Integration of visual and auditory information in bimodal neurones in the guineapig superior colliculus. Experimental Brain Research [Experimentelle Hirnforschung], 60, 492-500.

Koshino, H., Carpenter, P.A., Minshew, N.J., Cherkassky, V.L., Keller, T.A., \& Just, M.A. (2005). Functional connectivity in an fMRI working memory task in high-functioning autism. NeuroImage, 24, 810-821.

Koshino, H., Kana, R.K., Keller, T.A., Cherkassky, V.L., Minshew, N.J., \& Just, M.A. (2008). fMRI investigation of working memory for faces in autism: Visual coding and underconnectivity with frontal areas. Cerebal Cortex, 18, 289-300.

Kwakye, L.D., Foss-Feig, J.H., Cascio, C.J., Stone, W.L., \& Wallace, M.T. (2011). Altered auditory and multisensory temporal processing in autism spectrum disorders. Frontiers in Integrative Neuroscience, 4, 129.

Lamb, T.D., \& Pugh, E.N. Jr. (1992). A quantitative account of the activation steps involved in phototransduction in amphibian photoreceptors. The Journal of Physiology, 449, 719-758.

Lange, N., Dubray, M.B., Lee, J.E., Froimowitz, M.P., Froehlich, A., Adluru, N., ... Lainhart, J.E. (2010). Atypical diffusion tensor hemispheric asymmetry in autism. Autism Research, 3, 350-358.

Lee, J.E., Bigler, E.D., Alexander, A.L., Lazar, M., DuBray, M.B., Chung, M.K., ... McMahon, W.M. (2007). Diffusion tensor imaging of white matter in the superior temporal gyrus and temporal stem in autism. Neuroscience Letters, 424, 127-132.

Lennie, P. (1981). The physiological basis of variations in visual latency. Vision Research, 21, 815-824.

Levitt, J.G., Blanton, R.E., Smalley, S., Thompson, P.M., Guthrie, D., McCracken, J.T., ... Toga, A.W. (2003). Cortical sulcal maps in autism. Cerebal Cortex, 13, 728-735.

Lewis, R., \& Noppeney, U. (2010). Audiovisual synchrony improves motion discrimination via enhanced connectivity between early visual and auditory areas. Journal of Neuroscience, 30, 12329-12339.

Lewkowicz, D.J. (1996). Perception of auditory-visual temporal synchrony in human infants. Journal of Experimental Psychology: Human Perception and Performance, 22, 1094.

Lewkowicz, D.J. (2000). The development of intersensory temporal perception: An epigenetic systems/limitations view. Psychological Bulletin, 126, 281.

Lewkowicz, D.J., \& Ghazanfar, A.A. (2009). The emergence of multisensory systems through perceptual narrowing. Trends in Cognitive Science, 13, 470-478. 
Lewkowicz, D.J., \& Lickliter, R. (2013). The development of intersensory perception: Comparative perspectives. Psychology Press, Hillsdale, NJ.

Lovelace, C.T., Stein, B.E., \& Wallace, M.T. (2003). An irrelevant light enhances auditory detection in humans: A psychophysical analysis of multisensory integration in stimulus detection. Cognitive Brain Research, 17, 447-453.

Macaluso, E., George, N., Dolan, R., Spence, C., \& Driver, J. (2004). Spatial and temporal factors during processing of audiovisual speech: A PET study. NeuroImage, 21, 725-732.

MacDonald, J., \& McGurk, H. (1978). Visual influences on speech perception processes. Perception \& Psychophysics, 24, 253-257.

McGurk, H., \& MacDonald, J. (1976). Hearing lips and seeing voices. Nature, 264, 746-748.

McPartland, J., Dawson, G., Webb, S.J., Panagiotides, H., \& Carver, L.J. (2004). Event-related brain potentials reveal anomalies in temporal processing of faces in autism spectrum disorder. Journal of Child Psychology and Psychiatry, $45,1235-1245$.

Meredith, M.A., Nemitz, J.W., \& Stein, B.E. (1987). Determinants of multisensory integration in superior colliculus neurons. I. Temporal factors. Journal of Neuroscience, 7, 3215-3229.

Meredith, M.A., Wallace, M.T., \& Stein, B.E. (1992). Visual, auditory and somatosensory convergence in output neurons of the cat superior colliculus: Multisensory properties of the tecto-reticulo-spinal projection. Experimental Brain Research [Experimentelle Hirnforschung], 88, 181-186.

Miller, J. (1982). Divided attention: Evidence for coactivation with redundant signals. Cognitive Psychology, 14, 247-279.

Miller, L.M., \& D’Esposito, M. (2005). Perceptual fusion and stimulus coincidence in the cross-modal integration of speech. Journal of Neuroscience, 25, 5884-5893.

Minshew, N.J., \& Hobson, J.A. (2008). Sensory sensitivities and performance on sensory perceptual tasks in highfunctioning individuals with autism. Journal of Autism and Developmental Disorders, 38, 1485-1498.

Miyazaki, M., Yamamoto, S., Uchida, S., \& Kitazawa, S. (2006). Bayesian calibration of simultaneity in tactile temporal order judgment. Nature Neuroscience, 9, 875-877.

Molholm, S., Ritter, W., Murray, M.M., Javitt, D.C., Schroeder, C.E., \& Foxe, J.J. (2002). Multisensory auditory-visual interactions during early sensory processing in humans: A highdensity electrical mapping study. Brain Research: Cognitive Brain Research, 14, 115-128.

Mongillo, E.A., Irwin, J.R., Whalen, D.H., Klaiman, C., Carter, A.S., \& Schultz, R.T. (2008). Audiovisual processing in children with and without autism spectrum disorders. Journal of Autism and Developmental Disorders, 38, 1349-1358.

Morein-Zamir, S., Soto-Faraco, S., \& Kingstone, A. (2003). Auditory capture of vision: Examining temporal ventriloquism. Brain Research: Cognitive Brain Research, 17, 154-163.

Mottron, L., Dawson, M., Soulieres, I., Hubert, B., \& Burack, J. (2006). Enhanced perceptual functioning in autism: An update, and eight principles of autistic perception. Journal of Autism and Developmental Disorders, 36, 27-43.

Murray, M.M., Foxe, J.J., Higgins, B.A., Javitt, D.C., \& Schroeder, C.E. (2001). Visuo-spatial neural response interactions in early cortical processing during a simple reaction time task: A high-density electrical mapping study. Neuropsychologia, 39, 828-844.

Murray, M.M., \& Spierer, L. (2009). Auditory spatio-temporal brain dynamics and their consequences for multisensory interactions in humans. Hearing Research, 258, 121-133.

Nath, A.R., \& Beauchamp, M.S. (2011a). Dynamic changes in superior temporal sulcus connectivity during perception of noisy audiovisual speech. Journal of Neuroscience, 31, 1704-1714.

Nath, A.R., \& Beauchamp, M.S. (2012). A neural basis for interindividual differences in the Mcgurk effect, a multisensory speech illusion. NeuroImage, 59, 781-787.

Nath, A.R., Fava, E.E., \& Beauchamp, M.S. (2011). Neural correlates of interindividual differences in children's audiovisual speech perception. Journal of Neuroscience, 31, 1396313971.

Navarra, J., Vatakis, A., Zampini, M., Soto-Faraco, S., Humphreys, W., \& Spence, C. (2005). Exposure to asynchronous audiovisual speech extends the temporal window for audiovisual integration. Cognitive Brain Research, 25, 499-507.

O’Neill, M., \& Jones, R.S. (1997). Sensory-perceptual abnormalities in autism: A case for more research? Journal of Autism and Developmental Disorders, 27, 283-293.

Pasalar, S., Ro, T., \& Beauchamp, M.S. (2010). TMS of posterior parietal cortex disrupts visual tactile multisensory integration. The European Journal of Neuroscience, 31, 17831790.

Patten, E., Watson, L.R., \& Baranek, G.T. (2014). Temporal synchrony detection and associations with language in young children with ASD. Autism Research and Treatment, 8, doi: $10.1155 / 2014 / 678346$.

Pellicano, E., \& Burr, D. (2012). When the world becomes 'too real': A Bayesian explanation of autistic perception. Trends in Cognitive Sciences, 16, 504-510.

Pelphrey, K.A., \& Carter, E.J. (2008a). Charting the typical and atypical development of the social brain. Development and Psychopathology, 20, 1081-1102.

Pelphrey, K.A., \& Carter, E.J. (2008b). Brain mechanisms for social perception: Lessons from autism and typical development. Annals of the New York Academy of Sciences, 1145, 283-299.

Pöppel, E., Schill, K., \& von Steinbüchel, N. (1990). Sensory integration within temporally neutral systems states: A hypothesis. Naturwissenschaften, 77, 89-91.

Powers, A.R. 3rd, Hevey, M.A., \& Wallace, M.T. (2012). Neural correlates of multisensory perceptual learning. Journal of Neuroscience, 32, 6263-6274.

Powers, A.R. 3rd, Hillock, A.R., \& Wallace, M.T. (2009). Perceptual training narrows the temporal window of multisensory binding. Journal of Neuroscience, 29, 12265-12274.

Puce, A., Epling, J.A., Thompson, J.C., \& Carrick, O.K. (2007). Neural responses elicited to face motion and vocalization pairings. Neuropsychologia, 45, 93-106.

Redcay, E., \& Courchesne, E. (2008). Deviant functional magnetic resonance imaging patterns of brain activity to speech in 2-3-year-old children with autism spectrum disorder. Biological Psychiatry, 64, 589-598.

Roach, N.W., Heron, J., Whitaker, D., \& McGraw, P.V. (2011). Asynchrony adaption reveals neural population code for 
audio-visual timing. Proceedings of the Royal Society, 278, 9.

Rogers, S.J., Hepburn, S., \& Wehner, E. (2003). Parent reports of sensory symptoms in toddlers with autism and those with other developmental disorders. Journal of Autism and Developmental Disorders, 33, 631-642.

Ross, L.A., Molholm, S., Blanco, D., Gomez-Ramirez, M., SaintAmour, D., \& Foxe, J.J. (2011). The development of multisensory speech perception continues into the late childhood years. The European Journal of Neuroscience, 33, 2329-2337.

Royal, D.W., Carriere, B.N., \& Wallace, M.T. (2009). Spatiotemporal architecture of cortical receptive fields and its impact on multisensory interactions. Experimental Brain Research [Experimentelle Hirnforschung], 198, 127-136.

Russo, N., Foxe, J.J., Brandwein, A.B., Altschuler, T., Gomes, H., \& Molholm, S. (2010). Multisensory processing in children with autism: High-density electrical mapping of auditory-somatosensory integration. Autism Research, 3, 253-267.

Schall, S., Quigley, C., Onat, S., \& Konig, P. (2009). Visual stimulus locking of EEG is modulated by temporal congruency of auditory stimuli. Experimental Brain Research [Experimentelle Hirnforschung], 198, 137-151.

Schiltz, C., Bodart, J.M., Dubois, S., Dejardin, S., Michel, C., Roucoux, A., ... Orban, G.A. (1999). Neuronal mechanisms of perceptual learning: Changes in human brain activity with training in orientation discrimination. NeuroImage, 9, 46-62.

Schlack, A., Sterbing-D'Angelo, S.J., Hartung, K., Hoffmann, K.P., \& Bremmer, F. (2005). Multisensory space representations in the macaque ventral intraparietal area. Journal of Neuroscience, 25, 4616-4625.

Schlesinger, J.J., Stevenson, R.A., Shotwell, M.S., \& Wallace, M.T. (2014). Improving pulse oximetry pitch perception with multisensory perceptual training. Anesthesia and Analgesia, 118, 1249-1253.

Schroger, E., \& Widmann, A. (1998). Speeded responses to audiovisual signal changes result from bimodal integration. Psychophysiology, 35, 755-759.

Seitz, A.R., Nanez, J.E. Sr., Holloway, S.R., \& Watanabe, T. (2006). Perceptual learning of motion leads to faster flicker perception. PLoS ONE 1, e28.

Sekiyama, K., Kanno, I., Miura, S., \& Sugita, Y. (2003). Auditoryvisual speech perception examined by fMRI and PET. Neuroscience Research, 47, 277-287.

Senkowski, D., Talsma, D., Grigutsch, M., Herrmann, C.S., \& Woldorff, M.G. (2007). Good times for multisensory integration: Effects of the precision of temporal synchrony as revealed by gamma-band oscillations. Neuropsychologia, $45,561-571$.

Shams, L., Kamitani, Y., \& Shimojo, S. (2000). Illusions. What you see is what you hear. Nature, 408, 788.

Shih, P., Keehn, B., Oram, J.K., Leyden, K.M., Keown, C.L., \& Muller, R.A. (2011). Functional differentiation of posterior superior temporal sulcus in autism: A functional connectivity magnetic resonance imaging study. Biological Psychiatry, 70, 270-277.

Sinha, P., Kjelgaard, M.M., Gandhi, T.K., Tsourides, K., Cardinaux, A.L., Pantazis, D., ... Held, R.M. (2014). Autism as a disorder of prediction. Proceedings of the National Academy of Sciences of the United States of America, 111, 15220-15225.

Soto-Faraco, S., Kingstone, A., \& Spence, C. (2006). Integrating motion information across sensory modalities: The role of top-down factors. Progress in Brain Research, 155, 273-286.

Stein, B.E., Huneycutt, W.S., \& Meredith, M.A. (1988). Neurons and behavior: The same rules of multisensory integration apply. Brain Research, 448, 355-358.

Stein, B.E., Meredith, M., Huneycutt, W., \& McDade, L. (1989). Behavioral indices of multisensory integration: Orientation to visual cues is affected by auditory stimuli. Journal of Cognitive Neuroscience, 1, 12-24.

Stevenson, R.A., Altieri, N.A., Kim, S., Pisoni, D.B., \& James, T.W. (2010). Neural processing of asynchronous audiovisual speech perception. NeuroImage, 49, 3308-3318.

Stevenson, R.A., Bushmakin, M., Kim, S., Wallace, M.T., Puce, A., \& James, T.W. (2012). Inverse effectiveness and multisensory interactions in visual event-related potentials with audiovisual speech. Brain Topography, 25, 308-326.

Stevenson, R.A., Fister, J.K., Barnett, Z.P., Nidiffer, A.R., \& Wallace, M.T. (2012). Interactions between the spatial and temporal stimulus factors that influence multisensory integration in human performance. Experimental Brain Research [Experimentelle Hirnforschung].

Stevenson, R.A., Ghose, D., Fister, J.K., Sarko, D.K., Altieri, N.A., Nidiffer, A.R., ... \& Wallace, M.T. (2014). Identifying and quantifying multisensory integration: a tutorial review. Brain topography, 27, 707-730.

Stevenson, R.A., \& James, T.W. (2009). Audiovisual integration in human superior temporal sulcus: Inverse effectiveness and the neural processing of speech and object recognition. NeuroImage, 44, 1210-1223.

Stevenson, R.A., Kim, S., \& James, T.W. (2009). An additivefactors design to disambiguate neuronal and areal convergence: Measuring multisensory interactions between audio, visual, and haptic sensory streams using fMRI. Experimental Brain Research, 198, 183-194.

Stevenson, R.A., Segers, M., Ferber, S., Barense, M.D., \& Wallace, M.T. (2014). The impact of multisensory integration deficits on speech perception in children with autism spectrum disorders. Frontiers in Psychology, 5, 379.

Stevenson, R.A., Siemann, J.K., Schneider, B.C., Eberly, H.E., Woynaroski, T.G., Camarata, S.M., \& Wallace, M.T. (2014). Multisensory temporal integration in autism spectrum disorders. Journal of Neuroscience, 34, 691-697.

Stevenson, R.A., Siemann, J.K., Woynaroski, T.G., Schneider, B.C., Eberly, H.E., Camarata, S.M., \& Wallace, M.T. (2014a). Evidence for diminished multisensory integration in autism spectrum disorders. Journal of Autism and Developmental Disorders, 44, 3161-3167.

Stevenson, R.A., Siemann, J.K., Woynaroski, T.G., Schneider, B.C., Eberly, H.E., Camarata, S.M., \& Wallace, M.T. (2014b). Brief report: Arrested development of audiovisual speech perception in autism spectrum disorders. Journal of Autism and Developmental Disorders, 44, 1470-1477.

Stevenson, R.A., VanDerKlok, R.M, Pisoni, D.B., \& James, T.W. (2011). Discrete neural substrates underlie complementary audiovisual speech integration processes. NeuroImage, 55, 1339-1345. 
Stevenson, R.A., \& Wallace, M.T. (2013). Multisensory temporal integration: Task and stimulus dependencies. Experimental Brain Research [Experimentelle Hirnforschung Experimentation Cerebrale], 227, 249-261.

Stevenson, R.A., Wilson, M.M., Powers, A.R., \& Wallace, M.T. (2013). The effects of visual training on multisensory temporal processing. Experimental Brain Research [Experimentelle Hirnforschung Experimentation Cerebrale], 225, 479-489.

Stevenson, R.A., Zemtsov, R.K., \& Wallace, M.T. (2012). Individual differences in the multisensory temporal binding window predict susceptibility to audiovisual illusions. Journal of Experimanetal Psychology: Human Perception and Performance, 38, 1517.

Sumby, W.H., \& Pollack, I. (1954). Visual contribution to speech intelligibility in noise. The Journal of the Acoustical Society of America, 26, 212-215.

Szelag, E., Kowalska, J., Galkowski, T., \& Pöppel, E. (2004). Temporal processing deficits in high-functioning children with autism. British Journal of Psychology, 95, 269-282.

Talay-Ongan, A., \& Wood, K. (2000). Unusual sensory sensitivities in autism: A possible crossroads. International Journal of Disability and Developmental Education, 47, 201-212.

Treisman, A. (1996). The binding problem. Current Opinion in Neurobiology, 6, 171-178.

van Atteveldt, N.M., Blau, V.C., Blomert, L., \& Goebel, R. (2010). fMR-adaptation indicates selectivity to audiovisual content congruency in distributed clusters in human superior temporal cortex. BMC Neuroscience, 11, 11.

van Atteveldt, N.M., Formisano, E., Blomert, L., \& Goebel, R. (2007). The effect of temporal asynchrony on the multisensory integration of letters and speech sounds. Cerebal Cortex, 17, 962-974.

van Boxtel, J.J., \& Lu, H. (2013). A predictive coding perspective on autism spectrum disorders. Frontiers in Psychology, 4, 19.

Van de Cruys, S., Evers, K., Van der Hallen, R., Van Eylen, L., Boets, B., de-Wit, L., \& Wagemans, J. (2014). Precise minds in uncertain worlds: Predictive coding in autism. Psychological Review, 121, 649-675.

Van der Burg, E., Olivers, C.N., Bronkhorst, A.W., \& Theeuwes, J. (2008). Pip and pop: Nonspatial auditory signals improve spatial visual search. Journal of Experimanetal Psychology: Human Perception and Performance, 34, 1053-1065.

van der Smagt, M.J., van Engeland, H., \& Kemner, C. (2007). Brief report: Can you see what is not there? Low-level auditory-visual integration in autism spectrum disorder. Journal of Autism and Developmental Disorders, 37, 2014-2019.

van Eijk, R.L., Kohlrausch, A., Juola, J.F., \& van de Par, S. (2008). Audiovisual synchrony and temporal order judgments: Effects of experimental method and stimulus type. Perception \& Psychophysics, 70, 955-968.

van Wassenhove, V., Grant, K.W., \& Poeppel, D. (2007). Temporal window of integration in auditory-visual speech perception. Neuropsychologia, 45, 598-607.
Vatakis, A., Navarra, J., Soto-Faraco, S., \& Spence, C. (2008). Audiovisual temporal adaptation of speech: Temporal order versus simultaneity judgments. Experimental Brain Research [Experimentelle Hirnforschung], 185, 521-529.

Vroomen, J., \& Keetels, M. (2010). Perception of intersensory synchrony: A tutorial review. Attention, Perception \& Psychophysics, 72, 871-884.

Vroomen, J., Keetels, M., de Gelder, B., \& Bertelson, P. (2004). Recalibration of temporal order perception by exposure to audio-visual asynchrony. Cognitive Brain Research, 22, 3235.

Wallace, M.T., Roberson, G.E., Hairston, W.D., Stein, B.E., Vaughan, J.W., \& Schirillo, J.A. (2004). Unifying multisensory signals across time and space. Experimental Brain Research [Experimentelle Hirnforschung], 158, 252-258.

Watling, R.L., Deitz, J., \& White, O. (2001). Comparison of sensory profile scores of young children with and without autism spectrum disorders. The American Journal of Occupational Therapy, 55, 416-423.

Williams, J., Massaro, D.W., Peel, N.J., Bosseler, A., \& Suddendorf, T. (2004). Visual-auditory integration during speech imitation in autism. Research in Developmental Disabilities, 25, 559-575.

Wing, L., \& Potter, D. (2002). The epidemiology of autistic spectrum disorders: Is the prevalence rising? Mental Retardation and Developmental Disabilities Research Reviews, 8, 151-161.

Woynaroski, T.G., Kwakye, L.D., Foss-Feig, J.H., Stevenson, R.A., Stone, W.L., \& Wallace, M.T. (2013). Multisensory speech perception in children with autism spectrum disorders. Journal of Autism and Developmental Disorders, 43, 2891-2902.

Zampini, M., Guest, S., Shore, D.I., \& Spence, C. (2005). Audio-visual simultaneity judgments. Perception \& Psychophysics, 67, 531-544.

Zampini, M., Shore, D.I., \& Spence, C. (2003). Audiovisual temporal order judgments. Experimental Brain Research [Experimentelle Hirnforschung], 152, 198-210.

Zampini, M., Shore, D.I., \& Spence, C. (2005). Audiovisual prior entry. Neuroscience Letters, 381, 217-222.

Zilbovicius, M., Boddaert, N., Belin, P., Poline, J.B., Remy, P., Mangin, J.F., ... Samson, Y. (2000). Temporal lobe dysfunction in childhood autism: A PET study. Positron emission tomography. The American Journal of Psychiatry, 157, 1988-1993.

Zilbovicius, M., Meresse, I., \& Boddaert, N. (2006). [Autism: Neuroimaging]. Revista Brasileira de Psiquiatria, 28(Suppl 1), S21-S28.

Zilbovicius, M., Meresse, I., Chabane, N., Brunelle, F., Samson, Y., \& Boddaert, N. (2006). Autism, the superior temporal sulcus and social perception. Trends in Neurosciences, 29, 359-366. 